NBER WORKING PAPER SERIES

\title{
UNDERSTANDING PEER EFFECTS IN FINANCIAL DECISIONS: EVIDENCE FROM A FIELD EXPERIMENT
}

\author{
Leonardo Bursztyn \\ Florian Ederer \\ Bruno Ferman \\ Noam Yuchtman \\ Working Paper 18241 \\ http://www.nber.org/papers/w18241 \\ NATIONAL BUREAU OF ECONOMIC RESEARCH \\ 1050 Massachusetts Avenue \\ Cambridge, MA 02138 \\ July 2012
}

We would like to thank Sushil Bikhchandani, Aislinn Bohren, Arun Chandrasekhar, Shawn Cole, Rui de Figueiredo, Fred Finan, Uri Gneezy, Dean Karlan, Navin Kartik, Larry Katz, Peter Koudijs, Kory Kroft, Nicola Lacetera, David Laibson, Edward Leamer, Phil Leslie, Annamaria Lusardi, Kristof Madarasz, Gustavo Manso, Ted Miguel, Kris Mitchener, Adair Morse, Paul Niehaus, Andrew Oswald, Yona Rubinstein, Andrei Shleifer, Ivo Welch, as well as numerous seminar participants for helpful comments and suggestions. Juliana Portella provided excellent research assistance. We also thank the Garwood Center for Corporate Innovation, the Russell Sage Foundation and UCLA CIBER for financial support. Finally, we thank the management and staff of the cooperating brokerage firm for their efforts during the implementation of the study. There was no financial conflict of interest in the implementation of the study; no author was compensated by the partner brokerage or by any other entity for the production of this article. The views expressed herein are those of the authors and do not necessarily reflect the views of the National Bureau of Economic Research.

NBER working papers are circulated for discussion and comment purposes. They have not been peerreviewed or been subject to the review by the NBER Board of Directors that accompanies official NBER publications.

(C) 2012 by Leonardo Bursztyn, Florian Ederer, Bruno Ferman, and Noam Yuchtman. All rights reserved. Short sections of text, not to exceed two paragraphs, may be quoted without explicit permission provided that full credit, including $(\mathcal{C}$ notice, is given to the source. 
Understanding Peer Effects in Financial Decisions: Evidence from a Field Experiment Leonardo Bursztyn, Florian Ederer, Bruno Ferman, and Noam Yuchtman

NBER Working Paper No. 18241

July 2012, Revised February 2013

JEL No. C93,D03,D14,D83,G0,G11,M31

\begin{abstract}
$\underline{\text { ABSTRACT }}$
Using a high-stakes field experiment conducted with a financial brokerage, we implement a novel design to separately identify two channels of social influence in financial decisions, both widely studied theoretically. When someone purchases an asset, his peers may also want to purchase it, both because they learn from his choice ("social learning") and because his possession of the asset directly affects others' utility of owning the same asset ("social utility"). We find that both channels have statistically and economically significant effects on investment decisions. These results can help shed light on the mechanisms underlying herding behavior in financial markets.
\end{abstract}

Leonardo Bursztyn

UCLA Anderson School of Management

110 Westwood Plaza

Los Angeles, CA 90095

bursztyn@ucla.edu

Florian Ederer

UCLA Anderson School of Management

110 Westwood Plaza

Los Angeles, CA 90095

florian.ederer@anderson.ucla.edu
Bruno Ferman

School of Business

The George Washington University

2201 G Street NW, Funger Hall, Suite 611

Washington, DC 20052

bferman@gwu.edu

Noam Yuchtman

Haas School of Business

University of California, Berkeley

Berkeley, CA 94720

and NBER

yuchtman@haas.berkeley.edu 


\section{Introduction}

People's choices often look like the choices made by those around them: we wear what is fashionable, we "have what they're having," and we try to "keep up with the Joneses." Such peer effects have been analyzed across several fields of economics and social psychology. ${ }^{1}$ Motivated by concerns over herding and financial market instability, an especially active area of research has examined the role of peers in financial decisions. Beyond studying whether peers affect financial decisions, different channels through which peer effects work have generated their own literatures linking peer effects to investment decisions, and to financial market instability. Models of herding and assetprice bubbles, potentially based on very little information, focus on learning from peers' choices (Bikhchandani and Sharma, 2000; Chari and Kehoe, 2004). Models in which individuals' relative income or consumption concerns drive their choice of asset holdings, and artificially drive up some assets' prices, focus on peers' possession of an asset. ${ }^{2}$ In this paper, we use a high-stakes field experiment, conducted with a financial brokerage, to separately identify the causal effects of these channels through which a person's financial decisions are affected by his peers'.

Identifying the causal effect of one's peers' behavior on one's own is notoriously difficult (see, for example, Manski, 1993). Correlations in the investment or consumption choices of socially-related individuals might arise without any causal peer effect: for example, peers select into social groups

\footnotetext{
${ }^{1}$ In the economics literature, theoretical models of herding and social learning include Banerjee (1992) and Bikhchandani et al. (1992). Becker (1991) studies markets in which a consumer's demand for a product depends on the aggregate demand for the product. Social influence has also been analyzed under assumptions of bounded rationality, as in DeMarzo et al. (2003) and Guarino and Jehiel (forthcoming). Moscarini et al. (1998) study social learning when the state of the world is changing. Calvo-Armengol and Jackson (2010) examine peer pressure as a form of social influence. Empirical work on peer effects has studied a wide range of contexts: the impact of classmates or friends on education, compensation, and other outcomes (Sacerdote, 2001; Carrell and Hoekstra, 2010; de Giorgi et al., 2010; Duflo et al., 2011; Card and Giuliano, 2011; Shue, 2012); the impact of one's peers and community on social indicators and consumption (Bertrand et al., 2000; Kling et al., 2007; Bobonis and Finan, 2009; Dahl et al., 2012; Grinblatt et al., 2008; Kuhn et al., 2011); and, the impact of coworkers on workplace performance (Guryan et al., 2009; Mas and Moretti, 2009; Bandiera et al., 2010). Herding behavior and informational cascades (Celen and Kariv, 2004) and the impact of cultural primes on behavior (Benjamin et al., 2010) have been studied in the lab. Durlauf (2004) surveys the literature on neighborhood effects. Within the social psychology literature, Asch (1951) studied individuals' conformity to group norms; Festinger (1954) posited that one resolves uncertainty by learning from others; Burnkrant and Cousineau (1975) distinguished between "informational" and "normative" reasons for conformity.

${ }^{2}$ Preferences over relative consumption can arise from the (exogenous) presence of other individuals' consumption decisions in one's utility function, (e.g. Abel, 1990, Gali, 1994, Campbell and Cochrane, 1999) or can arise endogenously when one consumes scarce consumption goods, the prices of which depend on the incomes (and consumption and investment decisions) of other individuals (DeMarzo et al., 2004, DeMarzo et al., 2008). For an overview, see Hirshleifer and Teoh (2003).
} 
according to their preferences and characteristics, and this might generate correlated choices; peers share common environments (and changes in those environments), and this, too, might generate correlated choices. Equally difficult is identifying why one's consumption or investment choices have a social component. Broadly, there are two reasons why a peer's act of purchasing an asset (or product, more generally) would affect one's own choice:

(i) One infers that assets (or products) purchased by others are of higher quality; we refer to this as social learning.

(ii) One's utility from possessing an asset (or product) depends directly on the possession of that asset (or product) by another individual; we call this social utility.

Suppose an investor $i$ considers purchasing a financial asset under uncertainty. In canonical models of herding based on social learning (e.g., Banerjee, 1992 and Bikhchandani et al., 1992), information that a peer, investor $j$, purchased the asset will provide favorable information about the asset to investor $i$ : investor $j$ (acting in isolation) would only have purchased the asset if he observed a relatively good signal of the asset's return. The favorable information conveyed by investor $j$ 's revealed preference increases the probability that investor $i$ purchases the asset, relative to making a purchase decision without observing his peer's decision. ${ }^{3}$

In our study, we focus on social learning arising only from the information one acquires from the fact that one's peer purchased a financial product. We abstract away from the additional information one might acquire after a peer's purchase (e.g., by talking to the peer and learning about the quality of a product) and from any change in behavior due to increased salience of a product when consumed by one's peers. ${ }^{4}$ The impact of learning from a peer's purchase decision is the social learning channel.

Typically, investor $j$ 's decision to purchase the asset will also imply that investor $j$ possesses the asset. If investor $j$ 's possession of the asset directly affects investor $i$ 's utility of owning the

\footnotetext{
${ }^{3}$ Avery and Zemsky (1998) present a model in which information based herds do not occur, due to price adjustments; however, in our setting there is no asset price adjustment (see also Chari and Kehoe, 2004).

${ }^{4}$ The asset sold in our field experiment was designed to make this abstraction possible. This is discussed in detail in Section 2.1.
} 
same asset, then observing investor $j$ purchasing the asset (implying investor $j$ 's possession of the asset) can increase the likelihood that investor $i$ purchases the asset for reasons other than social learning.

A direct effect of investor $j$ 's possession of a financial asset on investor $i$ 's utility might arise for a variety of reasons widely discussed in the finance literature. First, investors may be concerned with their incomes or consumption levels, relative to their peers' ("keeping up with the Joneses", as in Abel, 1990, Gali, 1994, and Campbell and Cochrane, 1999). ${ }^{5}$ Investors will thus want to purchase assets possessed by their peers in order to avoid falling behind if the assets' prices rise. Another potential source of a direct effect of investor $j$ 's possession of a financial asset on investor $i$ 's utility is "joint consumption" of the asset: peers can follow and discuss financial news together, track returns together, etc. ${ }^{6}$ The impact of a peer's possession of an asset on an individual's utility derived from owning the same asset (for multiple reasons) is the social utility channel. ${ }^{7}$

A comparison of investor $i$ 's investment when no peer effect is present to the case in which he observes investor $j$ purchasing an asset will generally identify the combined social learning and social utility channels. To disentangle social learning from social utility, one needs to identify, or create, a context in which investor $j$ 's decision to purchase an asset is decoupled from investor $j$ 's possession of the asset (in Appendix A - note that all appendices are online - we present a model of peer effects in financial decisions that features both the social learning and social utility channels, and formalizes the discussion above).

Our experimental design (discussed in detail in Section 2) represents an attempt to surmount both the challenge of identifying a causal peer effect, and the challenge of separately identifying

\footnotetext{
${ }^{5}$ Evidence consistent with individuals caring about relative outcomes has been presented by Luttmer (2005), Fliessbach et al. (2007), and Card et al. (2010), among others.

${ }^{6} \mathrm{~A}$ recent Reuters article (Taylor, 2011) states, "Not that long ago, it seemed like everyone belonged to an investment club. People would gather at a friend's house, share a few bottles of merlot and toast their soaring investments in Cisco and JDS Uniphase." The article notes that the number of investment clubs peaked at 60,000 before the burst of the tech bubble.

${ }^{7}$ Note that even in the absence of truly "social" preferences, one might observe greater demand for an asset simply because a peer holds it: for example, this might arise as a result of competition over scarce consumption goods. Because we do not wish to abuse the term, "social preferences," we prefer the broader term, "social utility," which will include social preferences, as well as general equilibrium-induced differences in demand. Note also that in principle, social utility might lead to negative correlations between peers' choices (see Clark and Oswald, 1998). For example one might observe a demand for joint insurance (see, for instance, Angelucci et al., 2012). We focus here on the case of positive social utility effects, as these are predominant in the literature on peer effects in financial decisions.
} 
the effects of social learning and social utility. Working closely with us, a large financial brokerage in Brazil offered a new financial asset, designed exclusively for our experiment, to pairs of clients who share a social relationship (either friends or family members). The stakes were high: minimum investments were $\mathrm{R} \$ 2,000$ (over $\$ 1,000$ U.S. dollars at the time of the study), around $50 \%$ of the median investor's monthly income in our sample; furthermore, investors were not allowed to convert existing investments with the brokerage to purchase the asset and thus were required to allocate new resources in order to purchase the asset.

To identify any sort of peer effect on investment decisions, we randomly informed one member of the peer pair, investor 2 , of the investment made by the other member of the pair, investor 1 (assignment to the roles of investor 1 and investor 2 was random). To disentangle the effect of investor 1's possession from the effect of the information conveyed by investor 1's revealed preference (his decision to purchase the asset), we exploit a novel aspect of our experimental design. The financial brokerage with which we worked implemented a lottery to determine whether individuals who chose to purchase the asset would actually be allowed to make the investment (see Figure 1 for a graphical depiction of the experimental design). Thus, half of the investor 1's who chose to purchase the asset revealed a preference for the financial asset, but did not possess it.

Among investor 1's who chose to purchase the asset, we implemented a second, independent randomization to determine the information received by the associated investor 2's: we randomly assigned investor 2 to receive either no information about investor 1's investment decision, or to receive information about both the investment decision and the outcome of the lottery determining possession. Thus, among investor 1's who chose to purchase the asset, the associated investor 2's were randomly assigned to one of three conditions: (1) no information about investor 1's decision ${ }^{8}$; (2) information that investor 1 made a decision to purchase the asset, but was not able to consummate the purchase (so learning occurred without possession); or, (3) information that investor 1 made a decision to purchase the asset, and was able to consummate the purchase (so learning occurred, along with possession). A comparison of choices made by investor 2 in conditions (1) and

\footnotetext{
${ }^{8}$ We attempted to ensure that no information spread independently of the brokers' phone calls by requiring that calls be made to both investors on the same day. Our results are robust to dropping the $4 \%$ of investor 2's who had communicated with their associated investor 1's about the asset prior to the phone call from the brokerage.
} 
(2) reveals the effect of social learning; a comparison of (2) and (3) reveals the impact of investor 1's possession of the asset over and above the information conveyed by his purchase; a comparison of (1) and (3) reveals the total effect of these two channels. This design allows us to separately identify contributions of social learning and social utility in generating the overall peer effects we observe. $^{9}$

Our experimental evidence suggests that both channels through which peer effects work are important. Among investor 2's whose peer chose to purchase the asset we find the following: among individuals in the no information control condition, $42 \%$ chose to purchase the asset; among those informed that investor 1 wanted the asset, but was unable to purchase it, the take-up rate increased to $71 \%$; finally, among those informed that investor 1 wanted the asset, and was able to purchase it, the rate increased to $93 \%$. There are large, statistically significant peer effects; in addition, we find that each channel - social utility and social learning - is individually economically and statistically significant. We find that individuals learn from their peers, but also that there is an effect of possession beyond learning. This is true not only for the purchase decision, but also for the decision of whether to invest more than the minimum investment amount, and how much to invest in the asset. ${ }^{10}$

To better understand investors' decision making in the different conditions, we partnered with the brokerage to conduct a follow-up survey of the investors in the study (see Section 2.5 for details). We first use the evidence from that survey to further analyze the social learning channel. If investors differ in their level of financial sophistication, a natural extension of our analysis of social learning is to explore heterogeneity along that dimension. ${ }^{11}$ One would expect that an investor

\footnotetext{
${ }^{9}$ In Section 3.3.3, we discuss alternative interpretations of the treatment effects that we observe. Note that it is difficult to quantitatively estimate the effect of possession above learning, because the purchase rate in condition (3) is very close to $100 \%$. Because the purchase rate is bounded above, we estimate what may roughly be thought of as a lower bound of the effect of possession beyond learning.

${ }^{10}$ Our design also allows us to examine the role played by selection into a socially-related pair in generating correlated choices among peers. In particular, when investor 1 chose not to purchase the asset, his associated investor 2 was assigned to a "negative selection" condition, in which no information was received about about the peer (the brokerage did not want to include experimental conditions in which individuals learned that their peer did not want the asset). These investor 2's receive information identical to that received by investor 2's in the control condition (1); however, the investor 2's in the "negative selection" condition are those whose peers specifically chose not to purchase the asset. Interestingly, we do not find large selection effects: the take-up rate in the "negative selection" group was $39 \%$, not very different from the take-up rate in condition (1).

${ }^{11}$ It is important to note that heterogeneity in treatment effects across investors with differing financial sophistication must be interpreted with caution, as sophistication was not randomly assigned across investors in our study.
} 
with a low (respectively, high) degree of financial sophistication would be more (less) likely to follow the revealed preference decisions of other investors, because he will rely less (more) on his own assessment of the quality of an asset. One would also expect the revealed preference decisions made by more (respectively, less) financially sophisticated investors to generate larger (smaller) social learning effects, because the purchasing decision reflects a more (less) precise signal of the asset's quality.

To measure investors' financial sophistication, in the follow-up survey, the brokerage asked investors to assess their own financial knowledge and also asked them several objective questions (see Sections 2.5 and 3.3 for further discussion). Consistent with our predictions, we find no significant effect of social learning among financially sophisticated investor 2's, and a large, significant social learning effect among unsophisticated investor 2's; the difference in social learning effects between these groups is statistically significant as well. We also find that the purchase decisions of financially sophisticated investor 1's were associated with much larger social learning effects than those of unsophisticated investor 1's.

The follow-up survey provides suggestive evidence on the mechanisms behind the increased take-up rates in conditions (2) and (3). We find that $67 \%$ of investor 2's in conditions (2) and (3) reported positively updating their beliefs about the quality of the asset after learning that their peer chose to purchase it, consistent with an effect of social learning. Moreover, investor 2's reported positively updating their beliefs about the asset differentially depending on their financial sophistication, and on that of their associated investor 1: unsophisticated investor 2's were more likely to report positive updating of their beliefs about the asset as a result of learning about their peer's purchase decision; and, decisions to purchase by sophisticated investor 1's were associated with a higher rate of positive updating by investor 2's.

Among investors who chose to purchase the asset in condition (3), we find interesting evidence suggestive of social utility effects: over $40 \%$ reported a desire to discuss the asset with their peer following purchase; $60 \%$ reported wanting to earn the same return as their peer; and, $80 \%$ reported thinking about what their peer could $d o$ with the returns from the asset.

The evidence from the follow-up survey additionally helps us rule out several alternative inter- 
pretations of the treatment effects we observe, as well as confounding factors (discussed further in Section 3.3.3). We consider - and present evidence against - the following: differential updating of beliefs about the quality of the asset between conditions (2) and (3); a desire to "get ahead of the Joneses" (or, conversely, a feeling of guilt) in condition (2); investor 2's in condition (2) purchasing the asset for their peer; and, investor 2's in condition (2) purchasing the asset to match their peer's inferred portfolio. We also combine evidence from the follow-up survey with results from a pilot of our study that did not include a lottery to authorize investments to suggest that the lottery did not significantly affect the behavior of investors or interact with the information provided in conditions (2) and (3). Evidence from the follow-up survey also indicates that investor 2's in conditions (2) and (3) were not concerned about their decisions being revealed to other clients - a potential issue since in condition (1) investors did not receive information about their peers. ${ }^{12}$

It is important to qualify our findings. First, we focus on the social learning described in classic models, such as Banerjee (1992) and Bikhchandani et al. (1992): learning that occurs upon observing a peer's revealed preference purchasing decision. Of course, there are other types of social learning in financial decisions, such as learning about the existence of an asset, or learning that occurs after a peer's purchase (e.g., about when to sell an asset). We purposefully shut down these channels in our study, but they are likely important, and deserve further study. Second, our treatment effects are estimated from the behavior of a particular sample of investors. In Section 3.3.4, we show that the investor 1's in our study who chose to purchase the asset are similar to those who chose not to make the purchase - this is important because our treatment effects of interest are conditional on investor 1's wanting to purchase the asset. We also show that the characteristics of our sample of investors - selected because they shared a social connection with another client - are roughly similar to those of the full set of clients of the main office of the brokerage with which we worked. This evidence suggests that our sample is of interest, though it is surely not representative of all investors. Third, in our study, information about peers was transmitted by a third party (brokers) during a high-stakes sales call. Importantly, sales calls similar to those used in the study are commonly made by the brokerage with which we worked, and account for a large

\footnotetext{
${ }^{12}$ In Section 3.3.3 we also discuss the role of the supply side (i.e., broker behavior) in generating our results.
} 
fraction of its sales. ${ }^{13}$ Indeed, the brokerage required that the design of the sales call, as well as the follow-up survey, be completely natural. Thus, these calls are a prevalent method of selling assets, and the decisions made by the investors in our study were natural; still, it is possible that direct information transmission among peers has different effects from those observed here.

Our work contributes most directly to the empirical literature on peer effects in investment decisions. Much of the evidence of peer effects in financial markets has been correlational (e.g., Hong et al., 2004, Hong et al., 2005, Ivkovic and Weisbenner, 2007, and Li, 2009); important exceptions are Duflo and Saez (2003) and Beshears et al. (2011), who use field experiments to identify more plausibly causal peer effects in retirement plan choices among co-workers. ${ }^{14}$

We also exploit experimental variation in the field to identify causal peer effects, in another important setting. However, our paper goes beyond the existing literature by using experimental variation to separately identify the causal roles of different channels of peer effects. ${ }^{15}$ Disentangling these channels is of more than academic interest: it can provide important, policy-relevant evidence on the sources of herding behavior in financial markets. Our findings of significant social learning and social utility effects suggest that greater information provision might mitigate - but not eliminate - herding behavior.

Our paper also contributes to the broader literature on social learning and peer effects. As in our work, several recent papers use information shocks to identify causal peer effects: for example, Frey and Meier (2004) and Chen et al. (2010) study contributions to public goods; Ayres et al. (2009), Costa and Kahn (2010), and Allcott (2011) study energy usage. However, the information shocks they exploit do not allow for the separate identification of the channels through which peer effects work.

\footnotetext{
${ }^{13}$ While brokers generally do not provide information about specific clients' purchases, discussions with the brokerage indicate that brokers regularly discuss the behavior of other investors in their sales calls. It is also worth noting that in the U.S., investors commonly turn to brokers for financial advice and to undertake transactions. Hung et al. (2008) find that nearly half of a broad sample of Americans used a financial services provider; of these, three-quarters used them for advice or to undertake transactions.

${ }^{14}$ Duflo and Saez (2003) find large, positive peer effects in decisions to enroll in retirement plans effects, while Beshears et al. (2011) find no positive peer effects in contributions to retirement accounts. One possible interpretation of the difference in these results is that peers in the former paper are members of a relatively small work unit, while in the latter they are simply employees (of similar ages) in the same, large corporation. Brown et al. (2008) use an instrumental variables strategy to identify a causal peer effect on stock ownership.

${ }^{15}$ Banerjee et al. (2011) study the diffusion of microfinance through social networks, and structurally estimate the importance of different potential channels linking peers' decisions.
} 
Identifying the effect of social learning alone is the focus of Cai et al. (2009) and Moretti (2011); they try to rule out the existence of peer effects through other channels (e.g., joint consumption) in the contexts they study (food orders in a restaurant and box office sales, respectively), but they do not experimentally manipulate the social utility channel. Cai et al. (2012) study the purchase of insurance in China, and use experimental variation in the field to identify the effects of different types of social learning in networks; Maertens (2012) uses non-experimental methods to study different channels of social influence in the decision to adopt a new crop; Cooper and Rege (2011) attempt to distinguish among peer effect channels in the lab. Our work is the first we know of that uses experimental variation in the field to isolate the effect of social learning and the separate effect of social utility. Our results corroborate models such as Banerjee (1992) and Bikhchandani et al. (1992), but indicate that peers' purchasing decisions have effects beyond social learning as well.

Finally, our experimental design, which allows us to separately identify the channels through which peer effects work, represents a methodological contribution. As we discuss in the conclusion, our design could be applied toward the understanding of social influence in areas such as education, advertising, health-promoting behavior, and technology adoption.

The paper proceeds as follows: in Section 2, we describe in detail our experimental design, which attempts to separately identify the channels through which peer effects work; in Section 3, we present our empirical specification and the results of our experiment, and discuss our findings; finally, in Section 4, we offer concluding thoughts.

\section{Experimental Design}

The primary goal of our design was to decouple a peer's decision to purchase the asset from his possession of the asset. We generated experimental conditions in which individuals would make decisions: 1) uninformed about any choices made by their peer; 2) informed of their peer's revealed preference to purchase an asset, but the (randomly determined) inability of the peer to make the investment; and, 3) informed of their peer's revealed preference to purchase an asset, and the peer's (randomly determined) successful investment. We now describe the design in detail; in particular, 
the structuring of a financial asset that possessed particular characteristics, and the implementation of multiple stages of randomization in the process of selling the asset.

\subsection{Designing the Asset}

The asset being offered needed to satisfy several requirements. Most fundamentally, there needed to be a possibility of learning from one's peers' decisions. In addition, because many of our comparisons of interest are among investor 2's whose associated investor 1's chose to purchase the asset, the asset needed to be sufficiently desirable that enough investor 1's would choose to purchase it. To satisfy these requirements, the brokerage created a new, risky asset specifically for this study. The asset is a combination of an actively-managed, open-ended long/short mutual fund and a real estate note (Letra de Crédito Imobiliário, or LCI) for a term of one year. The long/short fund seeks to outperform the interbank deposit rate (CDI, Certificado de Depósito Interbancário) by allocating investment funds to fixed-income assets, equity securities, and derivatives. The LCI is a low-risk asset that is attractive to personal investors because it is exempt from personal income tax; it can be thought of as an appealing, high-yield CD.

The LCI offered in this particular combination had somewhat better terms than the real estate notes that were usually offered to clients of the brokerage, thus generating sufficient demand to meet the experiment's needs. First, the return of the LCI offered in the experiment was $98 \%$ of the CDI, while the best LCI offered to clients outside of the experiment had a return of $97 \%$ of the CDI. In addition, the brokerage firm usually required a minimum investment of $\mathrm{R} \$ 10,000$ to invest in an LCI, while the offer in the experiment reduced the minimum investment threshold to $\mathrm{R} \$ 1,000$ (the long/short fund also required a minimum investment of $\mathrm{R} \$ 1,000)$. The brokerage piloted the sale of the asset (without using a lottery to determine possession), to clients other than those in the current study, in order to ensure a purchase rate of around $50 \%$.

Another requirement was that there be no secondary market for the asset, for several reasons. First, we hoped to identify the impact of learning from peers' decisions to purchase the asset, rather than learning from peers based on their experience possessing the asset. Investor 2 may have chosen not to purchase the asset immediately, in order to talk with investor 1, then purchase the asset from 
another investor. We wished to rule out this possibility. In addition, we did not want peer pairs to jointly make decisions about selling the asset. Finally, we did not want investor 2 to purchase the asset in hopes of selling it to investor 1 when investor 1's investment choice was not implemented by the lottery. In response to these concerns, the brokerage offered the asset only at the time of their initial phone call to the client - there was a single opportunity to invest - and structured the asset as having a fixed term with no resale - once the investment decision was made, the investor would simply wait until the asset matured and then collect his returns.

A final requirement, given our desire to decouple the purchase decision from possession, was that there must be limited entry into the fund to justify the lottery to implement purchase decisions. The brokerage was willing to implement the lottery design required, justified by the supply constraint for the asset they created for the study. At the individual level, the maximum investment in the LCI component was set at $\mathrm{R} \$ 10,000$.

\subsection{Selling the Asset}

To implement the study, we designed (in consultation with the financial brokerage) a script for sales calls that incorporated the randomization necessary for our experimental design (the translated script is available in Appendix C). ${ }^{16}$ The sales calls made by brokers possessed several important characteristics. First, the brokerage required that calls be as natural as possible. Sales calls had frequently been made by the brokerage in the past - accounting for approximately $70 \%$ of sales - and our script was made as similar as possible to these more typical calls. ${ }^{17}$ Second, the experimental calls were made by the individual brokers who were accustomed to working with the clients they called as part of the study; and, the calls only deviated from brokers' typical sales calls as required to implement the experimental design. Thus, we (and the brokerage) expected that clients would trust the broker's claims about their peer's choices, and to believe that the lottery would be implemented as promised (evidence from the follow-up survey, discussed in Section 3.3,

\footnotetext{
${ }^{16}$ We created the script using Qualtrics, a web-based platform that brokers would access and use to structure their call. Occasionally, Qualtrics was abandoned when the website was not accessible, and the brokers used Excel to generate the randomization needed to execute the experimental design. The treatment effects are very similar if we restrict ourselves to the Qualtrics calls (results available upon request).

${ }^{17}$ The brokerage reported that no client suspected that the calls were being made as part of an academic experiment, meaning our study falls into the category "natural field experiment" (Harrison and List, 2004).
} 
confirms this expectation). Third, because brokers were compensated based on the assets they sold, they were simply incentivized to sell the asset in each condition (rather than to confirm any particular hypothesis). ${ }^{18}$

Between January 26, and April 3, 2012, brokers called 150 pairs of clients whom the brokerage had previously identified as having a social connection ( $48 \%$ are members of the same family, and $52 \%$ are friends; see Table 1). ${ }^{19}$ It is important to note that, although the investors in this sample are not a random sample of the brokerage's clients, we find that their observable characteristics are roughly similar to the full set of clients of the brokerage's main office (compare Table 1, columns 1 and 8$)$.

Information on these clients' social relationships was available for reasons independent of the experiment: the firm had made note of referrals made by clients in the past. In the context of our experiment, this is particularly important because clients' social relationships would not have been salient to those whose sales call did not include any mention of their peer. We thus believe that without any mention of the offer being made to the other member of the peer pair, there will be no peer effect, though of course this may not be exactly true in reality. ${ }^{20}$

One member of the pair was randomly assigned to the role of "investor 1," while the second member was assigned to the role of "investor 2." ${ }^{21}$ Investor 1 was called by the brokerage and given

\footnotetext{
${ }^{18}$ Thus, brokers would have used the available information in each experimental treatment as effectively as possible. Any treatment effects measured can be thought of as the effects of information about a peer's choice (or choice plus possession) when that information is "optimally" used by a salesperson (we discuss the supply side in more detail in Section 3.3.3). Of course, in reality, information about peers' choices may be received from the peer (rather than from a salesperson), or may not be observed at all; the magnitudes of our effects should be interpreted with this in mind.

${ }^{19}$ In Table 1, we generally present means of the various investor characteristics. The exception is the earnings variable, the median of which is shown in order to mitigate the influence of outliers: while the median monthly income in our sample is $\mathrm{R} \$ 4,500$, one investor had monthly earnings of $\mathrm{R} \$ 200,000$. In addition to the brokerage's record of a pair's social relationship, investor 2 was directly asked about the nature of his relationship with investor 1, after investor 2 had decided whether to purchase the asset (investor 1 was not asked about investor 2 at all). Note that one of the authors (Bursztyn) was present for some of the phone calls. In addition, for those and many of the other calls, we had a research assistant present; see the image included in Appendix C. Finally, it is worth noting that the sample size was limited by the number of previously-identified socially-related pairs of clients, as well the brokerage's willingness to commit time to the experiment. The brokerage agreed (in advance of the calls) to reach 300 clients.

${ }^{20}$ We also asked the brokerage if any investor spontaneously mentioned their peer in the sales call, and the brokerage indicated that this never occurred. If an individual in condition (1) had thought about his peer's potential offer and purchase of the same asset, our measured peer effects would be attenuated.

${ }^{21} \mathrm{~A}$ comparison of the characteristics of investor 1's and investor 2's can be seen in Appendix B, Table A.1, columns 1 and 2. The randomization resulted in a reasonable degree of balance across groups: 4 of 5 tests of equality of mean characteristics across groups have p-values above 0.10 . One characteristic, gender, is significantly different across
} 
the opportunity to invest in the asset without any mention of their peer. The calls proceeded as follows. The asset was first described in detail to investor 1. After describing the investment strategy underlying the asset, the investor was told that the asset was in limited supply; in order to be fair to the brokerage's clients, any purchase decision would be confirmed or rejected by computerized lottery. If the investor chose to purchase the asset, he was asked to specify a purchase amount. Then, a computer would generate a random number from 1 to 100 (during the phone call), and if the number was greater than 50, the investment would be authorized; the investor was informed of the details of the lottery before making his purchase decision. ${ }^{22}$

Following the call to investor 1 , the brokerage called the associated investor 2 . The brokers were told that, for each pair, both investors had to be contacted on the same day to avoid any communication about the asset that might contaminate the experimental design. Only 6 out of 150 investor 2's had communicated with their associated investor 1's about the asset prior to the phone call from the brokerage (dropping these 6 observations does not affect any of our results). If the broker did not succeed in reaching investor 2 on the same day as the associated investor 1, the broker would not attempt to contact him again; this outcome occurred for 12 investor 1's, who are not included in our empirical analysis. ${ }^{23}$

When the broker reached investor 2, he began the script just as he did for investor 1: describing the asset, including the lottery to determine whether a purchase decision would be implemented. Next, the broker implemented the experimental randomization and attempted to sell the asset under the experimentally-prescribed conditions (described next). If investor 2 chose to purchase the asset, a random number was generated to determine whether the purchase decision would be implemented, just as was the case for investor 1.

${ }^{22}$ One might naturally be concerned that knowledge of the lottery would affect the decision to invest. This would, of course, be of greatest concern to us if any effect of the lottery interacted with treatment status (we discuss this in Section 3.3). It is reassuring to know, however, that in the brokerage's initial calls to calibrate the asset's purchase rate (our pilot study), which did not mention the lottery, the purchase rate was 12 of 25 , or $48 \%$ - very similar to what we observe among investors in our study receiving no information about their peers. Among investor 1's who wanted to purchase the asset, a comparison of the characteristics of investor 1's whose purchase decision was authorized and investor 1's whose purchase decision was not authorized can be seen in Appendix B, Table A.1. The randomization resulted in a reasonable degree of balance across groups: 5 of 6 tests of equality of mean characteristics across groups have p-values above 0.10 . One characteristic, gender, is significantly different across groups.

${ }^{23}$ Thus, to be clear, brokers called 162 investor 1's in order to attain our sample size of 150 pairs successfully reached.
} 


\subsection{Randomization into Experimental Conditions}

The experimental conditions were determined as follows. Among the group of investor 1's who chose to purchase the asset, their associated investor 2's were randomly assigned to receive information about investor 1's choice and the lottery outcome, or to receive no information. There was thus a "double randomization" - first, the lottery determining whether investor 1 was able to make the investment, and second, the randomization determining whether investor 2 would be informed about investor 1's investment choice and the outcome of the first lottery.

This process assigns investor 2's whose associated investor 1's chose to purchase the asset into one of three conditions (Figure 1 presents a graphical depiction of the randomization); investor characteristics across the three experimental conditions can be seen in Table 2. One-third were assigned to the "no information," control condition, condition (1). Half of these come from the pool of investor 2's paired with investor 1's who wanted the asset but were not authorized to make the investment, and half from those paired with investor 1's who wanted to make the investment and were authorized to make it. Investor 2's in condition (1) were offered the asset just as was investor 1 , with no mention of an offer made to their peer. ${ }^{24}$

Two-thirds received information about their peer's decision to purchase the asset (but not the magnitude of the desired investment), as well as the outcome of the lottery that determined whether the peer was allowed to invest in the asset. The randomization resulted in approximately one-third of investor 2's in condition (2), in which they were told that their peer purchased the asset, but had that choice rejected by the lottery. The final third of investor 2's were in condition (3), in which they were told that their peer purchased the asset, and had that choice implemented by the lottery.

The three conditions of investor 2's whose associated investor 1's wanted to purchase the asset are the focus of our analysis. Given the double randomization in our experimental design, investor 2's in conditions (1), (2), and (3) should have similar observable characteristics, and should differ only in the information they received. As a check of the randomization, we present in Table 2 the individual investors' characteristics for each of the three groups, as well as tests of equality of

\footnotetext{
${ }^{24}$ We can think of these investor 2's as "positively selected" relative to the set of investor 1's, as the latter were a random sample of investors, while the former are specifically those whose peer chose to purchase the asset.
} 
the characteristics across groups. As expected from the random assignment into each group, the sample is well balanced across the baseline variables.

Along with the three conditions of interest, in some analyses we will consider those investor 2's whose associated investor 1 chose not to invest in the asset (the characteristics of these investor 2's can be seen in Table 1, column 7). We assign these investor 2's to their own "negative selection" condition, in which they receive no information about their peer. We did not reveal their peers' choices because the brokerage did not want to include experimental conditions in which individuals learned that their peer did not want the asset. These individuals were offered the asset in exactly the same manner as were investor 1's and investor 2's in condition (1). We refer to these investor 2 's as those in the "negative selection" condition, because the information they receive is identical to that received by investor 2's in condition (1); however, the investor 2's in the "negative selection" condition are those whose peers specifically chose not to purchase the asset.

\subsection{Treatment Effects of Interest}

Our experimental design allows us to make several interesting comparisons across groups of investors. First, we can estimate overall peer effects, working through both social learning and social utility channels. Consider the set of investor 2's whose peers had chosen to purchase the asset (whether the investment was implemented or not). Among these investor 2's, a comparison of those in conditions (1) and (3) reveals the standard peer effect: in condition (1), there is no peer effect active, as no mention was made of any offer being made to the other member of the peer pair; in condition (3), the investor 2 is told that investor 1 successfully invested in the asset (so both social utility and social learning channels are active).

Second, we can disentangle the channels through which peers' purchases affect investment decisions. Comparing investor 2's (again those whose peer chose to purchase the asset) in conditions (1) and (2) will allow us to estimate the impact of social learning resulting from a peer's decision but without possession. Comparing investor 2's purchase decisions in conditions (2) and (3) will then allow us to estimate the impact of a peer's possession alone, over and above learning from 
a peer's decision, on the decision to invest. ${ }^{25}$ In addition to identifying these peer effects, we will examine the role of "selection", by comparing investor 2's in condition (1) to those in the "negative selection" condition.

\subsection{Follow-up Survey}

Between November 26, and December 7, 2012, the brokerage conducted a follow-up survey with a subset of the clients from the main study; investors were told (truthfully) that the brokerage wished to learn about its clients in order to provide them with more individualized services and information. The follow-up survey was conducted with two primary goals for the purposes of our work: first, to measure investors' financial sophistication; and second, to collect information that could be used to better understand the decision making processes behind the choices of investor 2's (for the English language survey questionnaires, see Appendix C).

In our analysis below, we examine heterogeneity in social learning effects among investor 2's in conditions (1) and (2), depending on whether investor 2 (or the associated investor 1) is financially sophisticated; this analysis not only tests a natural extension of a simple social learning model, but also helps rule out alternative explanations for the treatment effects we observe. To measure the relevant set of investors' financial sophistication, the brokerage contacted the investor 2's in conditions (1) and (2), as well as their associated investor 1's, and asked them to assess their own financial knowledge; in addition, the brokerage asked these investors a series of objective questions measuring financial literacy. ${ }^{26}$ For summary statistics on the financial sophistication survey questions, see Appendix B, Table A.2, Panel A.

We also collected survey evidence that can help us understand the decision making of investor

\footnotetext{
${ }^{25}$ It is important to emphasize that our estimated effect of possession is conditional on investor 2 having learned about the asset from the revealed preference of investor 1 to purchase the asset. One might imagine that the effect of possession of the asset by investor 1 without any revealed preference to purchase the asset could be different. It is also important to point out that the estimated effect of "possession" is difficult to interpret quantitatively: the measured effect is bounded above by 1 minus the take-up in condition (2), working against finding any statistically significant peer effects beyond social learning.

${ }^{26}$ The specific questions come from the National Financial Capability Survey (translated into Portuguese), and have been used in studies both in the US and in other countries (Lusardi and Mitchell, 2011a,b). Investor 2's other than those in conditions (1) and (2), and investor 1's other than those associated with investor 2's in conditions (1) and (2), were not asked these financial sophistication questions to reduce the brokerage's time commitment to the follow-up survey.
} 
2's across experimental conditions (1), (2), and (3). In particular, we wished to understand: (i) how investors viewed the lottery that determined whether purchase decisions were implemented (relevant to conditions (1), (2), and (3)); (ii) how investors responded to information about their peer's purchase decision (relevant to conditions (2) and (3)); (iii) how investors responded to information about the outcome of the lottery determining whether their peer's decision was implemented (relevant to conditions (2) and (3), though with different questions reflecting the different lottery outcomes); and, (iv) how investors responded to information about their peer's possession of the asset (relevant to condition (3)). For summary statistics on the decision making survey questions, see Appendix B, Table A.2, Panel B.

The brokerage conducted the follow-up survey over the phone, calling investor 2's in conditions (1), (2), and (3), and investor 1's associated with investor 2's in conditions (1) and (2), up to three times each; the brokerage was able to reach $90.4 \%$ of the investors called.

\section{Empirical Analysis}

Before more formally estimating the effects of the experimental treatments, we present the take-up rates in the raw data across categories of investor 2's (see Figure 2). Among those investor 2's in the "no information" condition (1), the take-up rate was $42 \%$; in the "social learning alone" condition (2), the take-up rate was $71 \%$; in the "social learning plus social utility" condition (3), the take-up rate was $93 \%$. These differences represent economically and statistically significant peer effects: the difference of around 50 percentage points in take-up rates between conditions (1) and (3) is large and statistically significant, indicating the relevance of peer effects in financial decisions; moreover, we observe sizable and statistically significant effects of learning alone, and of possession above learning as well. ${ }^{27}$ Interestingly, we do not see a big "selection" effect: there was a $42 \%$ take-up rate in condition (1) and $39 \%$ in the "negative selection" group (the difference is not statistically significant). In Appendix B, Figure A.1, we present the raw data on alternative outcomes of interest: the amount investors chose to invest in the asset (which was determined prior

\footnotetext{
${ }^{27}$ The p-value from a test of equality between take-up rates in conditions (1) and (3) - the overall peer effect - is 0.000. The p-value from a test that (2) equals $(1)$ - social learning alone - is 0.043 . The p-value from a test that (3) equals (2) - possession's effect above social learning - is 0.044 .
} 
to the lottery authorizing investment), and the fraction of clients who chose to invest more than the minimum, across conditions. The patterns across conditions are very similar to those seen in Figure 2.

A natural question about our findings in Figure 2 (and Figure A.1) is whether our statistical inferences are sound, given the relatively small number of observations in each experimental condition. Thus, as an alternative to standard t-tests to determine statistical significance, we ran permutation tests with 10,000 repetitions for pairwise comparisons of the raw outcomes - take-up rates, investment amounts, and investing more than the minimum - across the three conditions of interest (as well as a comparison between condition (1) and the "negative selection" condition). ${ }^{28}$ We find that our inferences are practically unchanged using permutation tests (see Appendix B, Table A.3, Panel A).

\subsection{Regression Specification}

To identify the effects of our experimental treatments, we will estimate regression models of the following form:

$$
Y_{i}=\alpha+\sum_{c} \beta_{c} I_{c, i}+\gamma^{\prime} \mathbf{X}_{i}+\epsilon_{i}
$$

$Y_{i}$ is an investment decision made by investor $i$ : in much of our analysis it will be a dummy variable indicating whether investor $i$ wanted to purchase the asset, but we will also consider the quantity invested, as well as an indicator that the investment amount was greater than the minimum required. The variables $I_{c, i}$ are indicators for investor $i$ being in category $c$, where $c$ indicates the experimental condition to which investor $i$ was assigned. In all of our regressions, the omitted category of investors to which the others are compared will be investor 2's in condition (1); that is, those investor 2's associated with a peer who wanted to purchase the asset, but who received no information about their peer. In much of our analysis, we will focus on investor 2's, so

\footnotetext{
${ }^{28}$ To run the permutation test, we randomly assign "treatment" status to investors in the groups of interest, 10,000 times, and calculate a distribution of "treatment effects" based on the random assignment. We then compare the size of the treatment effects we find (using the actual treatment assignment) to the distribution of "treatment effects" when treatment is randomly assigned.
} 
$c \in\{$ condition (2), condition (3), "negative selection" $\}$. In some cases, we will also include investor 1's in our analysis, and they will be assigned their own category c. Finally, in some specifications we will include control variables: $X_{i}$ is a vector that includes broker fixed effects and investors' baseline characteristics.

\subsection{Empirical Estimates of Social Utility and Social Learning}

We first present the estimated treatment effects of interest using an indicator of the investor's purchase decision as the outcome variable, and various specifications estimated using OLS, in Table $3 .^{29}$ We begin by estimating a model using only investor 2's and not including any controls, in Table 3, column 1. These results match the raw data presented in Figure 2: treatment effects are estimated relative to the omitted category, investor 2's in condition (1), who had a take-up rate of $42 \%$. As can be seen in the table, the overall peer effect - the coefficient on the indicator for condition (3) - is over 50 percentage points, and is highly significant.

In addition, social learning and social utility are individually significant. Investor 2's in condition (2) purchased the asset at a rate nearly 29 percentage points higher than those in condition (1), and the difference is significant. This indicates that learning without possession affects the investment decision. The difference between the coefficient on condition (3) and the coefficient on condition (2) indicates the importance of possession beyond social learning. Indeed, as can be seen in Table 3 , the 22 percentage point difference between these conditions is statistically significant.

Finally, the coefficient on the "negative selection" variable, in column 1 of Table 3 , gives us the difference in take-up rates between investor 2's whose peers did not want to purchase the asset and investor 2's whose peers wanted to purchase the asset, with neither group receiving information about their peers. As suggested by Figure 2, the estimated selection effect is economically small, and it is not statistically significant.

We next present regression results including broker fixed effects (Table 3, column 2) and including both broker fixed effects and baseline covariates (Table 3, column 3); then, we estimate a regression including these controls and using the combined sample of investor 1's and investor 2's in

\footnotetext{
${ }^{29}$ We also estimate the specifications from Table 3, but using probit and logit models, in Appendix B, Tables A.4 and A.5; results are very similar.
} 
order to have more precision (Table 3, column 4). The overall peer effect, as well as the individual social learning and social utility channels, estimated using these alternative regression models are very similar across specifications (consistent with successful randomization across conditions).

We also consider two alternative outcome variables: the amount investors chose to invest in the asset, and a dummy variable indicating whether the chosen investment amount was greater than the minimum required. In Table 4, we replicate the specifications presented in columns 1 and 4 in Table 3, but use each of the alternative outcome variables. As can be seen in Table 4, the results using these alternative outcomes closely parallel those using take-up rates. We observe significant peer effects, significant social learning, and significant effects of possession beyond learning. ${ }^{30}$

\subsection{Discussion}

The results across specifications in Tables 3 and 4 indicate sizable peer effects in financial decision making. Moreover, they suggest that both channels through which peer effects work are important. It is worth noting that the very large magnitudes of the peer effects we find may to some extent reflect the context of the experiment: the peers we study are very close - often friends or family in contrast to other work in this area (e.g., Beshears et al., 2011). ${ }^{31}$ Thus, both a desire to keep up with peers' earnings, and utility from joint consumption, might be especially pronounced in our setting. In addition, characteristics of the process of information transfer (e.g., the broker's ability to use information about one's peer in the sales call) may contribute to the relatively large effects we find.

We now delve more deeply into our data, and analyze investors' responses to the follow-up survey, in order to better understand the treatment effects we observe. We first present additional evidence on each of the two channels of social influence we study. Then, we discuss potential

\footnotetext{
${ }^{30}$ The only difference worth noting is that we observe marginally significant differences between investor 1 's and investor 2's in condition (1) using these two outcomes. This difference might be the result of noise in the data, of selection into condition (2), or of the somewhat earlier calls made to investor 1's. Although there are differences in the selection of investor 1's and investor 2's in condition (1), it is reassuring to note that our results are robust to treating investor 1's as part of the control group, or as the control group itself. Finally, it is important to note that differences between investor 1's and investor 2's in condition (2) do not threaten the study's internal validity.

${ }^{31} \mathrm{It}$ is also worth noting that the peers we study formed their associations naturally (and endogenously), which is not always true in academic studies. Carrell et al. (2011) find that naturally-occurring peer groups exhibit very different influence patterns from artificially-created peer groups.
} 
concerns with our experimental design and the interpretation of our results: alternative hypotheses (or confounding factors) that might contaminate our experimental treatments; whether supply-side (broker) behavior played an important role in generating the observed treatment effects; and, the external validity of our findings.

\subsubsection{Understanding the Social Learning Treatment Effects}

Heterogeneity of social learning effects by Financial Sophistication. When observing a peer's purchase of an asset, an investor with greater financial sophistication (and therefore a more precise signal of asset quality) should put less weight on information derived from their peer's revealed preference, relative his own signal of the quality of the asset. Similarly, the information conveyed by the revealed preference of one's peer should be more influential if this peer is more financially sophisticated, and is thus likely to have received a more precise signal of the asset's quality (see Appendix A for a formal treatment of these arguments). We thus expect that the social learning channel should be less important for more financially sophisticated investor 2's, and that the social learning channel should be more pronounced when investor 1's were more financially sophisticated.

Testing for heterogeneous social learning effects faces challenges: most importantly, financial sophistication is not randomly assigned in our study, so it might be correlated with some other, unobserved characteristic; in addition, testing for heterogeneous treatment effects divides our sample into small cells; thus, any evidence of heterogeneous treatment effects should be interpreted cautiously. ${ }^{32}$ Still, exploring heterogeneous treatment effects is both interesting from a theoretical standpoint - since it is a natural extension of a social learning framework - and it can also provide suggestive evidence that our measured social learning treatment effects are not driven by other factors (as we discuss below).

We construct two measures of investors' financial sophistication using responses to several questions included in our follow-up survey (for the English version of the questionnaire used in the

\footnotetext{
${ }^{32}$ One consequence of the small cell sizes is that we are unable to combine into a single analysis the study of social learning by sophisticated and unsophisticated investors with the study of social learning from sophisticated and unsophisticated investors. One might expect that the greatest effect of social learning would occur when unsophisticated investors learn from sophisticated ones; however, our sample size prevents us from running this sort of test.
} 
survey, see Appendix C; for summary statistics on the financial sophistication survey questions, see Appendix B, Table A.2, Panel A). Our first measure captures investors' self-assessments of their financial sophistication. The financial literacy survey directly asked investors: "On a scale from 1 to 7 , where 1 means very low and 7 means very high, how would you assess your overall financial knowledge?". Using the self-assessed measure, we define "financially sophisticated" investors as those who reported a number greater than or equal to 4, producing the most even split of our sample.

Our second measure captures investors' objective financial knowledge. The follow-up survey asked four questions testing respondents' understanding of important concepts for investing: one on compounding; one on inflation; one on diversification; and, one on the relationship between bond prices and interest rates. Using the objective measure, we define "financially sophisticated" investors as those who correctly answered 3 or more of the questions, again producing the most even split of our sample. Our two survey-based measures of financial sophistication have a correlation of around 0.4 within-investor: they are statistically significantly related, but far from perfectly so. Across peers in each pair, there is a surprisingly small correlation in financial sophistication: 0.06 for the self-assessed measure, and -0.11 for the objective measure.

In testing hypotheses regarding heterogeneity in social learning according to investor 2's financial sophistication, we believe that the self-assessed measure is most appropriate - investor 2's who view themselves as less knowledgeable are those who should respond more to information about their peer's revealed preference. In testing hypotheses regarding heterogeneity in social learning according to investor 1's financial sophistication, one might like to use a measure of investor 2's beliefs about investor 1's knowledge. Not having that available to us, we believe the objective measure of investor 1's sophistication may be appropriate here (as may the self-assessed measure, if this were broadcast to the peer, and believed). For brevity, in the text we will present tests of heterogeneity in social learning across both investor 1's and investor 2's levels of financial sophistication using only the self-assessed measure (in Appendix B, Table A.6, we present the same specifications shown in the text, but using the objective measure, and our results are very similar). ${ }^{33}$

\footnotetext{
${ }^{33}$ In previous versions of this paper, we used an investor's occupation as a proxy for his financial sophistication
} 
We present regression estimates of social learning effects for different categories of investor 2's, using different specifications, in Table 5. Panel A presents social learning treatment effects estimated from regressions without controls (i.e., comparisons of means). ${ }^{34}$ In columns $1-2$, we estimate separate social learning effects for financially sophisticated and financially unsophisticated investor 2's, respectively. We do so by regressing the investment decision dummy variable on a "financially sophisticated" indicator; an interaction between a condition (2) indicator and the financially sophisticated indicator; and, an interaction between a condition (2) indicator and a "financially unsophisticated" indicator. In columns 4-5, we estimate separate social learning effects for investor 2's associated with financially sophisticated and financially unsophisticated investor 1's, respectively. We do so by regressing the investment decision dummy variable on a "financially sophisticated investor 1" indicator; an interaction between a condition (2) indicator and the financially sophisticated investor 1 indicator; and, an interaction between a condition (2) indicator and a "financially unsophisticated investor 1" indicator. Panel B presents estimated social learning effects from models similar to those in Panel A, but also including baseline covariate controls and broker fixed effects.

The results in Table 5 match what one would predict if social learning were the driving force behind the treatment effects when comparing conditions (1) and (2). First, consider heterogeneity according to the financial sophistication of investor 2 ("learning by financially sophisticated"), in columns 1-2: in specifications with and without controls, we observe a small and, statistically insignificant effect of the social learning treatment on financially sophisticated investor 2's, and a large and significant effect on unsophisticated investor 2's. Column 3 shows that the difference between the treatment effects for sophisticated and unsophisticated investor 2's is also significant. Next, consider heterogeneity according to the financial sophistication of investor 1 ("learning from financially sophisticated") in columns 4-5: we find large and significant social learning effects among investor 2's associated with financially sophisticated investor 1's, and small, statistically

(occupations were coded as "financially sophisticated" either by the authors or, independently, by graduate students). Our results are very similar using this alternative measure of investors' financial sophistication as well.

${ }^{34}$ Note that in Table 5, our sample consists of only investor 2's in conditions (1) and (2). Also note that the outcome variable considered here is the take-up rate for the asset, but our results are very similar using alternative outcomes (amount invested or an indicator of an investment larger than the minimum); see Appendix B, Tables A.7 and A.8. 
insignificant effects among investor 2's associated with financially unsophisticated investor 1's (takeup rates across sub-groups are presented in Appendix B, Figures A.2.1 and A.2.2).

We consider a range of robustness tests. Using the objective measure of financial knowledge does not affect our results (see Appendix B, Table A.6). In previous drafts, we used investors' occupations as a proxy for their financial sophistication, and we found similar results; we have also coded our self-assessed financial sophistication indicator using a score of 5 as the cut-off, and considered a specification with a continuous measure of financial sophistication; our results are qualitatively similar across specifications (available upon request). Finally, one might be worried about our statistical inferences, since we are dividing our small treatment groups into even smaller cells. To address this concern, we ran permutation tests with 10,000 repetitions for each subgroup's social learning effect, and find that our statistical inferences from the regression models are unaffected (for the permutation test p-values, see Appendix B, Table A.3, Panel B).

Evidence of updated beliefs. We believe that investor 2's higher take-up rate in condition (2), and a component of their higher take-up rate in condition (3), resulted from positively updating their beliefs about the asset after hearing that their associated investor 1 chose to purchase it. While brokers did not elicit prior or posterior beliefs during the initial sales call, in the follow-up survey, investors in conditions (2) and (3) were directly asked whether the fact that their associated investor 1 wanted to purchase the asset affected their beliefs about the quality of the asset. We find that $67 \%$ of investor 2's in conditions (2) and (3) reported positively updating their beliefs about the quality of the asset after learning that their peer chose to purchase it, consistent with a social learning effect.

Our hypotheses regarding heterogeneous social learning effects according to investor 1's and investor 2's financial sophistication suggest that investor 2's should have updated their beliefs about the asset differentially depending on their financial sophistication, and that of their associated investor 1. Unsophisticated investor 2's should have been more likely to positively update their beliefs; and, purchase decisions by sophisticated investor 1's should have led to more positive belief updating. Indeed, we find precisely these patterns in the follow-up survey data. Among unsophisticated investor 2's in condition (2), 92\% reported positively updating their beliefs about 
the quality of the asset; among sophisticated ones, only $11 \%$ did (the p-value of this difference is less than 0.01). ${ }^{35}$ Among investor 2's in condition (2) associated with sophisticated investor 1's, we find that $69 \%$ positively updated their beliefs; among those associated with unsophisticated investor 1's, only 33\% updated positively (the p-value of this difference is 0.16 ).

\subsubsection{Understanding the Social Utility Treatment Effects}

The finance literature has pointed to different reasons why one's peer's possession of an asset might directly affect one's utility from possessing the same asset. In the follow-up survey, the investor 2's in condition (3) who chose to purchase the asset were asked about two particular mechanisms. First, they were asked about the importance of relative income or consumption concerns: whether earning the same return as their peer was important to their decision; whether fear of missing out on a return their peer might earn was important; and, whether they thought about what their peer might $d o$ with the returns from the asset. Second, they were asked one question relating to the importance of the "joint consumption" value of the financial asset: whether anticipated discussions of the asset with their peer were important to their decision.

The results indicate that both mechanisms were important. First, regarding "keeping up with the Joneses" motives: $60 \%$ of respondents reported that wanting to earn the same financial return as their peer was a significant factor in their decision; $80 \%$ of them reported that they thought about what their peer could do with the return from the asset; $32 \%$ reported that the fear of not having a return that their peer could have was a significant factor in their decision. We also find evidence of a "joint consumption" channel: $44 \%$ reported that a significant factor in their purchase decision was that they could talk with their peer about the asset.

Although we cannot cleanly identify the relative importance of these different mechanisms, the evidence from the follow-up survey suggests that relative income and consumption concerns and a desire for "joint consumption" both played a role in generating the social utility effects we observe. While investors did not need to select any of these social utility factors as playing a significant role in their decisions, only $4 \%$ of respondents did not point to any of them as a relevant element in

\footnotetext{
${ }^{35}$ One sophisticated investor 2 reported negatively updating his beliefs - the only such response in the survey.
} 
their decision making process.

\subsubsection{Alternative Hypotheses and Confounding Factors}

In an ideal experiment, our condition (2) would have differed from condition (1) only because of social learning; and, condition (3) would have differed from condition (2) only in the added effect of social utility. Of course, in reality, there may have been other differences across conditions, and here we discuss whether they were likely to have played an important role in generating the treatment

effects we observe. First, we consider the possibility that factors other than learning from investor 1's revealed preference affected outcomes in the social learning condition (2).

Consequences of learning about the peer's lost lottery. Investor 2's in condition (2) not only learned about their peer's revealed preference, they also learned that the lottery rejected that revealed preference. This might have affected their behavior in several ways. First, it might have increased the salience of the new asset's scarcity, making the asset appear more appealing, and increasing take-up rates. To examine this possibility, in the follow-up survey, we asked investor 2's in condition (2) whether their views of the asset's quality were affected by their peer's lottery outcome; $98 \%$ them said that they were not.

Information about the lottery outcome might also have affected take-up if investor 2's incorrectly updated their beliefs about their own likelihood of winning the lottery based on news of their peer's outcome. A reduced subjective probability of winning might have reduced take-up relative to condition (3), for example. Responses in the follow-up survey suggest that incorrect updating of beliefs about the lottery was likely unimportant: when asked if the information about their peer's lottery outcome affected their beliefs about their own lottery outcome, $100 \%$ of investor 2's in condition (2) reported that it did not.

Guilt or "getting ahead of the Joneses." We implicitly assume that investor 1's loss of the lottery only affected investor 2's by making social utility gains from asset possession unavailable. However, one might believe that investor 2's would feel guilt possessing an asset that their peer was prevented from acquiring; or, that investor 2's might especially desire an asset their peer explicitly could not acquire - perhaps out of a desire to "get ahead of the Joneses." Our follow-up survey 
can help us address these potential concerns. We asked the investor 2's in condition (2) who chose to make the investment whether the fact that their peer could not have the asset was a significant factor in their decision to purchase the asset, and all respondents replied "no." Analogously, we asked the investor 2's in condition (2) who chose not to make the investment whether the fact that their peer could not have the asset was a significant factor in their decision not to purchase the asset, and again all respondents replied "no."

One might worry that investors would be embarrassed to reveal a desire to get ahead of their peer. In evaluating the importance of a desire to get ahead of the Joneses, we are reassured by our results (in Table 5) showing heterogeneous effects of social learning depending on investor 1's and investor 2's financial sophistication. It is difficult to tell a story in which the desire to get ahead of one's peer is concentrated among the financially unsophisticated, and in particular among investor 2's whose associated investor 1 is financially sophisticated. Learning, rather than a desire to get ahead, is much more plausible given the heterogeneous treatment effects we find.

Side payments. Another potential concern with the social learning condition relates to side payments. Since investor 1's wanted, but could not get, the asset, some investor 2's may have felt tempted to make the investment and pass it along, or sell it, to their peer. Our design reduces the impact of this type of concern for several reasons. First, investor 1's who lost the lottery did not know that investor 2's would receive the offer, so investor 1's would likely not have initiated this strategy following their sales call. Second, even had they suspected that their friend would receive the offer, there was limited time between calls to investor 1's and investor 2's - indeed, only 6 out of 150 investor 2's reported that they heard about the asset from their associated investor 1 (our results are robust to dropping these 6 investor 2's). Finally, once investor 2 received the offer, he was unable to communicate with investor 1 prior to making his investment decision in order to facilitate coordination.

We can also address this concern to some extent with our experimental data. One might expect side payments, if present and important, to be most prominent among peers who are family members, as family members would have an easier time coordinating such payments than would mere friends or coworkers. This would tend to drive up the estimated social learning effect for pairs 
who are family members. In column 1 of Table 6 , we consider the full specification from column 4 of Table 3, but also including interactions of each of our condition dummy variables with a dummy variable equal to one if investor 1 and investor 2 are family members (and the main effect of the family member indicator). The results suggest that the treatment effects from social learning are not stronger among family members - the point estimate of the interaction is almost exactly zero. ${ }^{36}$

Desire to match peer's inferred portfolio. One might also think that knowing that a peer desired to purchase an asset (even if he was unable to make the purchase) provides an indication of that peer's portfolio, or future asset purchases outside of the study. As a result, the social learning condition could potentially also contain some (anticipated or approximate) possession effect. We believe this effect is likely to have been small for several reasons. First, the specific asset sold in the study was not otherwise available; and, even if an investor wished to approximately reconstruct the asset, this would have been difficult. The real estate note $(L C I)$ that we offered as a part of the asset is usually not available to this set of clients - they typically have access only to another real estate note at worse terms. In addition, the minimum investment in a real estate note is usually $\mathrm{R} \$ 10,000$ (instead of $\mathrm{R} \$ 1,000$ in our study), making entry into this sort of asset difficult. All this information was known to the investors in our sample, and as a result, they might infer that their peer would find it difficult to purchase similar assets outside of the study. Finally, there is no reason to expect possession effects based on inferences about investor 1's portfolio to drive investment decisions so disproportionately among unsophisticated investor 2's, and predominantly in response to choices made by sophisticated investor 1's.

There are also some concerns that could affect one's interpretation of both condition (2) and condition (3).

Sharing information with other clients. One concern with our design is that in condition (1), there is no mention of another investor's choice, while in conditions (2) and (3) there is. One might worry that investor 2's in condition (2) or (3) made their investment decisions while thinking about the possibility of their choices being discovered by their peers. A first concern is that their

\footnotetext{
${ }^{36}$ In Table 6, we present the coefficients on the interaction terms, but the full set of estimated coefficients is available from the authors upon request.
} 
purchase decision would be communicated to their peers by the brokerage. Importantly, however, the vast majority of our investors (all but 5) were known to have links with only one other client (their associated investor 1). Thus, once the offer was made to investor 1, investor 2 typically had no other peer who was a client of the brokerage, and who might receive the offer (and, in fact, no information about investor 2 was ever shared). Our results are robust to dropping the 5 investor 2's who were part of larger networks of clients (results available upon request). To further examine this concern, in the follow-up survey, we asked investor 2's in conditions (2) and (3) if they were concerned about the possibility that their purchase decision would be revealed to other clients. Only $11 \%$ of the respondents replied "yes," and our results are robust to dropping these investors (results available upon request).

Finally, investor 2's in conditions (2) and (3) might have felt a need to conform, anticipating their peer asking them about their decision after the phone call (although investor 1 was never provided with any information about their peer). However, the existence of the lottery to implement a purchase decision provided investor 2's with cover for a non-conforming choice, thus mitigating this concern. ${ }^{37}$

Effects of the lottery to authorize investments. One might wonder if the presence of the lottery significantly distorted decisions by making the asset appear to be extremely scarce and desirable. We do not believe this was the case. First, it is important to remember that the asset used in the study could not be re-sold on the market following purchase, so the lottery did not send a signal about external demand for the asset. Second, we can compare the take-up rates in our experiment to those in a prior pilot study without a lottery to authorize investments: the purchase rate in the pilot study was 12 of 25 , or $48 \%$ - very similar to what we observe among investors in our study receiving no information about their peers. Evidence from the follow-up survey is also informative: we asked investor 2's in conditions (1), (2), and (3) whether the presence of the lottery was a significant factor in their purchase decision. Only $4.3 \%$ of respondents reported that it was

\footnotetext{
${ }^{37}$ Hearing about a peer might also simply increase the attention an investor pays to the broker's sales pitch. While we cannot rule out a change in attention playing a role in our results, we believe that our findings of heterogeneous treatment effects and survey evidence on updated beliefs are more suggestive of actual learning than simply paying greater attention. For example, one's ears are likely to perk up when hearing about any peer's choice; but, one is more likely to learn from the choice of a sophisticated friend, just as we find.
} 
(and our results are robust to dropping them from our analysis). Finally, it is worth noting that the use of lotteries in the sale of financial assets is not as unusual as it may appear at first glance. For example, Instefjord et al. (2007) describe the use of lotteries to allocate shares when IPO's are oversubscribed.

Differential strength of revealed preference signal. Because our comparisons of interest are all among conditions that included the lottery, it is unlikely that a "level effect" of the lottery could generate the peer effects we observe. However, an especially important question is whether the lottery interacted with the information provided in condition (2) or (3). For example, our experimental design assumes that investor 1's revealed preference for the asset sends the same signal about asset quality regardless of whether the lottery awarded the asset to investor 1 . However, one might be concerned that in condition (3), learning that investor 1 possessed the asset might have enhanced the revealed preference signal, relative to condition (2). If so, this would imply that part of the treatment effect we observe in condition (3) is a social learning effect, rather than a social utility effect.

One possibility is that investor 2's in condition (2) believed that their associated investor 1's did not really want the asset, and the lottery result acted as a cover for this preference; in condition (3), on the other hand, the lottery outcome might have served as a signal that investor 1's really did want the asset. In the follow-up survey, we asked investor 2's in conditions (2) and (3) if they believed the information provided by the broker that their peer chose to purchase the asset, and 97\% replied "yes." This suggests that doubt about investor 1's purchase decision did not play an important role in investor 2's decisions. A related possibility is that investor 2's in conditions (2) and (3) viewed the lottery outcome as a signal of whether investor 1's chose to follow through with their purchase decision. In the follow-up survey, we asked investor 2's in conditions (1), (2), and (3) if, when making their decision, they thought they could change their choice after the realization of the lottery; $94 \%$ of them answered "no." Thus, it is unlikely that investor 2's viewed the purchase decision as non-binding, and the lottery as a signal of investor 1's true preferences. Our results are robust to dropping investors responding differently from the majority to either of these questions (results available upon request). 
We also examine direct evidence on belief updating in conditions (2) and (3). In the raw data from the follow-up survey, we find some evidence of more frequent positive belief updating in condition (3) than in condition (2): $57 \%$ of individuals in condition (2) reported positively updating their beliefs, while $74 \%$ of individuals in condition (3) did (the p-value on the difference is 0.23$)$. While this gap is of some concern, we have reason to believe that it does not explain the treatment effect we observe in condition (3). First, we estimate the full specification of our empirical model, Table 3, column 4, using the the follow-up survey's indicator of a positive belief update as the outcome, for investor 2's in conditions (2) and (3). We find that the point estimate of the coefficient on condition (3) is just 0.06 (with a p-value of 0.74 ; results available upon request). Thus, the evidence suggests that conditional on controls, the differential belief updating across conditions was very small, and unlikely to have driven our treatment effects.

In addition, we examine whether there was differential take-up across experimental conditions among investors who did not positively update their beliefs. If differential belief updating (rather than deciding to invest due to social utility motives) drove the higher take-up rate in condition (3), one would expect similar (relatively low) take-up rates among investors in conditions (2) and (3) who did not positively update their beliefs. Although sample sizes are small, we find qualitative evidence supportive of social utility effects. Among investor 2's who did not positively update their beliefs, the purchase rate was $56 \%$ in condition (2), and $71 \%$ in condition (3), suggesting that investors in condition (3) were more likely to have additional motives for purchasing the asset.

Changes in supply side behavior. Our study manipulates information received by agents on the demand side of a financial market. Of course, there is a supply side in this market as well, and one might be concerned that supply-side factors interact with our experimental treatments. For example, brokers could exert differential effort toward selling the asset under different experimental conditions; more generally, the experiment was not double blind, which might affect the implementation of the design.

Fortunately, we believe that the impact of the supply side on our measured treatment effects was likely limited. First, because brokers were compensated based on the assets they sold, they were incentivized to sell the asset in all conditions, rather than to confirm any particular hypothesis. 
If broker effort did vary across conditions, one might have expected brokers to learn how to use the information in the various conditions more effectively as they made more sales calls. Thus, if broker behavior was important in generating our results, one would expect a significant interaction between a broker's prior experience in the experiment and the experimental conditions. We estimate the full specification of Table 3, column 4, but including an interaction of each condition dummy variable with a measure of broker experience in the study: for each date of the study, we calculate the number of calls each broker had made before that date (we also include the main effect of broker experience). The estimates of these interactions, presented in Table 6 , column 2 , show that broker experience does not significantly affect the estimated treatment effects, suggesting that brokers were not driving the treatment effects we observe. ${ }^{38}$

\subsubsection{External Validity}

A final important concern with our design regards the external validity of the findings. There are several important qualifications to the generality of the treatment effects we estimate. First, it is important to note that the type of social learning on which we focus is that of classic models, such as Banerjee (1992) and Bikhchandani et al. (1992): learning that occurs upon observation of the revealed preference decision to purchase made by a peer. Of course, there are other types of social learning that might occur in finance, such as learning about the existence of an asset, or learning occurring after the purchase (when to sell the asset, when to buy more); these channels are shut down in our study because of the design of the financial asset. However, these other forms of social learning are likely important as well.

Second, our treatment effects are estimated from the behavior of a particular sample of investors. Our comparisons among investor 2's in conditions (1), (2), and (3) are conditional on investor 1 choosing to purchase the asset. If this was an unusual sample of investor 1's, perhaps the associated investor 2's were unusual as well, and thus generate peer effects that cannot be viewed

\footnotetext{
${ }^{38}$ In Table 6, we present the coefficients on the interaction terms, but the full set of estimated coefficients is available from the authors upon request. We have also examined the effects of broker experience within the experiment using a less parametric specification, plotting take-up rates by experimental condition, across quartiles of broker experience in the study. We find that social learning and social utility effects are remarkably consistent across quartiles (results available upon request).
} 
as representative even within our experimental sample. In fact, when comparing investor 1's who chose to purchase the asset to those who chose not to purchase it, one sees that their observable characteristics are very similar (see Table 1, columns 3 and 4). The investor 2's associated with investor 1's who chose to purchase the asset are also similar to those associated with investor 1's who chose not to purchase it (see Table 1, columns 6 and 7). We also find that, among investor 2's receiving no information about their peers, investor 2's associated with investor 1's who chose to purchase the asset (condition (1)) have a similar purchase rate to investor 2's associated with investor 1's who chose not to purchase the asset ("negative selection"); see Table 3. This suggests that conditioning on investor 1's wanting to purchase the asset does not produce an unusual subsample from which we estimate treatment effects.

Another concern is that our experimental sample of investors might be atypical: we study the behavior of investors who had referred (or had been referred by) other clients to the brokerage in the past. One might wonder how different our sample of investors is from other clients of the brokerage. In Table 1, column 8, we present characteristics of the full set of the brokerage's clients from the firm's main office. Although the clients in our study's sample are not a random sample of the brokerage's clients, we find that their observable characteristics are roughly similar to the full set of clients of the main office. This evidence suggests that our sample is of interest, though it is surely not representative of all investors.

Finally, one may question the representativeness of the form of communication studied in our experiment. Certainly, peers often communicate among themselves, rather than being informed about each other's activity by a broker trying to make a sale. ${ }^{39}$ Our study focuses on third-party communication generating peer effects. Importantly, the sorts of calls we study are widely used: the brokerage informed us that sales calls similar to those in the study account for approximately $70 \%$ of its sales. ${ }^{40}$ Of course, in interpreting the magnitude of our effects, one might wish to consider the

\footnotetext{
${ }^{39}$ Duflo and Saez (2003) present evidence that information about investment opportunities does flow naturally among peers; our goal of disentangling separate channels of peers' influence required control over information flows.

${ }^{40}$ While brokers generally do not provide information about specific clients' purchases, discussions with the brokerage indicate that brokers regularly discuss the behavior of other investors in their sales calls. It is also worth noting that in the U.S., investors commonly turn to brokers for financial advice and to undertake transactions. Hung et al. (2008) find that nearly half of a broad sample of Americans used a financial services provider; of these, three-quarters used them for advice or to undertake transactions.
} 
likelihood of information transfer in the real world; our design estimates the impact of information about one's peers conditional on receiving information - the endogenous acquisition of information is not studied here.

\section{Conclusion}

Peer effects are an important, and often confounding, topic of study across the social sciences. In many settings - particularly in finance - identifying why a person's choices are affected by his peers' is extremely important, beyond identifying peer effects overall. Our experimental design not only allows us to identify peer effects in investment decisions, it also decouples revealed preference from possession, allowing us to provide evidence that learning from one's peer's purchase decision and changing behavior due to a peer's possession of an asset both affect investment decisions.

Our findings should be extended in several directions. Most fundamentally, it is important to determine their external validity. We are limited to studying a single asset; a single mechanism through which peers' choices were communicated; and, pairs of socially-related individuals. One might be interested in whether our findings extend to assets with different expected returns or different exposures to risk; or, to investment decisions made from a larger choice set. One might also wish to study whether information transmitted directly among peers has a different effect from information transmitted through brokers. Of course, the selection of information transmitted by brokers and by peers will be endogenous, and studying the process determining which information gets transmitted, and to whom, would be of great interest. Finally, studying information transmission through a broader network of socially-related individuals is important as well.

To the extent that our results do shed light on financial decision making beyond our experimental context, it is important to understand what they imply for asset pricing and for policies that attempt to limit financial market instability. For example, herds based on social learning could be mitigated if more, and better, information is made available to investors. On the other hand, information provision will be less successful in limiting correlated choices among peers if those correlated choices are driven by social utility. Our findings suggest that information provision could reduce market 
instability, but only to a certain point, because a significant component of the peer effects we find was generated by social utility. Our results also point to an important interaction between financial literacy and herding behavior, which deserves further study.

In addition to the context of financial decision making, our experimental design could be used in other settings to identify the channels through which peer effects work. In marketing, various social media rely on different peer effect channels: Facebook "likes", Groupon sales, and product give-aways all rely on some combination of the channels studied here. Future work can compare the effectiveness of these strategies, and their impact through different channels, using designs similar to ours. One could also apply our experimental design to the study of technology adoption: one might wish to distinguish between learning from a peer's purchase decision and the desire to adopt technologies used by people nearby. ${ }^{41}$ Finally, health-promoting behavior often is affected both by learning from peers' purchases and by peers' actual use of health care technology (e.g., vaccination or smoking cessation). ${ }^{42}$ In these settings and others, separately identifying the roles of social learning and social utility might be of interest to policymakers.

\section{References}

Abel, Andrew B., "Asset Prices under Habit Formation and Catching Up with the Joneses," American Economic Review, 1990, 80 (2), 38-42.

Allcott, Hunt, "Social Norms and Energy Conservation," Journal of Public Economics, 2011, 95, $1082-1095$.

Angelucci, Manuela, Giacomo de Giorgi, and Imran Rasul, "Resource Pooling Within

Family Networks: Insurance and Investment," March 2012. Stanford University Working Paper.

\footnotetext{
${ }^{41}$ Foster and Rosenzweig (1995) and Conley and Udry (2010) identify the important role played by social learning in technology adoption. Social utility might exist in this setting because using a technology might be easier or less expensive when others nearby use it (network externalities); because one wishes not to fall behind those living nearby; etc.

${ }^{42}$ One can also learn about health care products from a peer's experience of the product - a type of learning we do not consider in this study. Kremer and Miguel (2007) study the transmission of knowledge about de-worming medication through social networks. Sorensen (2006) studies social learning in employees' choices of health plans.
} 
Asch, Salomon E., "Effects of Group Pressure on the Modification and Distortion of Judgments," in Harold Guetzkow, ed., Groups, Leadership and Men, Pittsburgh, PA: Carnegie Press, 1951, pp. $177-190$.

Avery, Christopher and Peter Zemsky, "Multidimensional Uncertainty and Herd Behavior in Financial Markets," American Economic Review, 1998, 88 (4), 724-748.

Ayres, Ian, Sophie Raseman, and Alice Shih, "Evidence from Two Large Field Experiments that Peer Comparison Feedback Can Reduce Residential Energy Usage," 2009. NBER Working Paper 15386.

Bandiera, Oriana, Iwan Barankay, and Imran Rasul, "Social Incentives in the Workplace," Review of Economic Studies, April 2010, 77 (2), 417-459.

Banerjee, Abhijit V., "A Simple Model of Herd Behavior," Quarterly Journal of Economics, 1992, $107(3), 797-817$.

_, Arun G. Chandrasekhar, Esther Duflo, and Matthew O. Jackson, "The Diffusion of Microfinance," August 2011. MIT Department of Economics Working Paper.

Becker, Gary S., "A Note on Restaurant Pricing and Other Examples of Social Influences on Price," Journal of Political Economy, October 1991, 99 (5), 1109-1116.

Benjamin, Daniel J., James J. Choi, and A. Joshua Strickland, "Social Identity and Preferences," American Economic Review, September 2010, 100 (4), 1913-1928.

Bertrand, Marianne, Erzo F. P. Luttmer, and Sendhil Mullainathan, "Network Effects and Welfare Cultures," Quarterly Journal of Economics, August 2000, 115 (3), 1019-1055.

Beshears, John, James J. Choi, David Laibson, Brigitte C. Madrian, and Katherine L. Milkman, "The Effect of Providing Peer Information on Retirement Savings Decisions," August 2011. NBER Working Paper 17345.

Bikhchandani, Sushil and Sunil Sharma, "Herd Behavior in Financial Markets: A Review," 2000. IMF Working Paper No. 00/48. 
_, David Hirshleifer, and Ivo Welch, "A Theory of Fads, Fashion, Custom, and Cultural Change as Informational Cascades," Journal of Political Economy, 1992, 100 (5), 992-1026.

Bobonis, Gustavo and Frederico Finan, "Neighborhood Peer Effects in Secondary School Enrollment Decisions," Review of Economics and Statistics, 2009, 91 (4), 695-716.

Brown, Jeffrey R., Zoran Ivkovic, Paul A. Smith, and Scott Weisbenner, "Neighbors Matter: Causal Community Effects and Stock Market Participation," Journal of Finance, June 2008, 63 (3), 1509-1531.

Burnkrant, Robert E. and Alain Cousineau, "Informational and Normative Social Influence in Buyer Behavior," Journal of Consumer Research, 1975, 2 (3), 206-215.

Cai, Hongbin, Yuyu Chen, and Hanming Fang, "Observational Learning: Evidence from a Randomized Natural Field Experiment," American Economic Review, 2009, 99 (3), 864-882.

Cai, Jing, Alain De Janvry, and Elisabeth Sadoulet, "Social Networks and the Decision to Insure," October 2012. University of Michigan Working Paper.

Calvo-Armengol, Antoni and Matthew O. Jackson, "Peer Pressure," Journal of the European Economic Association, January 2010, 8 (1), 62-89.

Campbell, John Y. and John H. Cochrane, "By Force of Habit: A Consumption-Based Explanation of Aggregate Stock Market Behavior," Journal of Political Economy, 1999, 107 (2), $205-251$.

Card, David, Alexandre Mas, Enrico Moretti, and Emmanuel Saez, "Inequality at Work: The Effect of Peer Salaries on Job Satisfaction," 2010. NBER Working Paper 16396.

_ and Laura Giuliano, "Peer Effects and Multiple Equilibria in the Risky Behavior of Friends," May 2011. NBER Working Paper 17088.

Carrell, Scott E. and Mark L. Hoekstra, "Externalities in the Classroom: How Children Exposed to Domestic Violence Affect Everyone's Kids," American Economic Journal: Applied Economics, January 2010, 2 (1), 211-228. 
_ , Bruce I. Sacerdote, and James E. West, "From Natural Variation to Optimal Policy? The Lucas Critique Meets Peer Effects," 2011. NBER Working Paper 16865.

Celen, Bogachan and Shachar Kariv, "Distinguishing Informational Cascades from Herd Behavior in the Laboratory," American Economic Review, 2004, 94 (3), 484-497.

Chari, Varadarajan V. and Patrick J. Kehoe, "Financial Crises as Herds: Overturning the Critiques," Journal of Economic Theory, 2004, 119 (1), 128-150.

Chen, Yan, F. Maxwell Harper, Joseph Konstan, and Sherry Xin Li, "Social Comparisons and Contributions to Online Communities: A Field Experiment on MovieLens," American Economic Review, September 2010, 100 (4), 1358-1398.

Clark, Andrew E. and Andrew J. Oswald, "Comparison-concave Utility and Following Behaviour in Social and Economic Settings," Journal of Public Economics, 1998, 70 (1), 133-155.

Conley, Timothy G. and Christopher R. Udry, "Learning about a New Technology: Pineapple in Ghana," American Economic Review, March 2010, 100 (1), 35-69.

Cooper, David J. and Mari Rege, "Misery Loves Company: Social Regret and Social Interaction Effects in Choices Under Risk and Uncertainty," Games and Economic Behavior, September 2011, 73 (1), 91-110.

Costa, Dora and Matthew E. Kahn, "Energy Conservation "Nudges" and Environmentalist Ideology: Evidence from a Randomized Residential Electricity Field Experiment," 2010. NBER Working Paper 15939.

Dahl, Gordon B., Katrine V. Loken, and Magne Mogstad, "Peer Effects in Program Participation," June 2012. UC-San Diego Working Paper.

de Giorgi, Giacomo, Michele Pellizzari, and Silvia Redaelli, "Identification of Social Interactions through Partially Overlapping Peer Groups," American Economic Journal: Applied Economics, April 2010, 2 (2), 241-275. 
DeMarzo, Peter M., Dimitri Vayanos, and Jeffrey Zwiebel, "Persuasion Bias, Social Influence, and Unidimensional Opinions," Quarterly Journal of Economics, August 2003, 118 (3), 909-968.

_, Ron Kaniel, and Ilan Kremer, "Diversification as a Public Good: Community Effects in Portfolio Choice," The Journal of Finance, 2004, 59 (4), 1677-1716.

_ , _, and _ , "Relative Wealth Concerns and Financial Bubbles," Review of Financial Studies, 2008, 21 (1), 19-50.

Duflo, Esther and Emmanuel Saez, "The Role of Information and Social Interactions in Retirement Plans Decisions: Evidence from a Randomized Experiment," Quarterly Journal of Economics, 2003, $118(3), 815-842$.

_, Pascaline Dupas, and Michael Kremer, "Peer Effects, Teacher Incentives, and the Impact of Tracking: Evidence from a Randomized Evaluation in Kenya," American Economic Review, 2011, 101 (5), 1739-1774.

Durlauf, Steven N., "Neighborhood Effects," Handbook of Regional and Urban Economics, 2004, 4.

Festinger, Leon, "A Theory of Social Comparison Processes," Journal: Human Relations, 1954, 7, $117-140$.

Fliessbach, Klaus, Bernd Weber, Peter Trautner, Thomas J. Dohmen, Uwe Sunde, Christian E. Elger, and Armin Falk, "Social Comparison Affects Reward-Related Brain Activity in the Human Ventral Striatum," Science, 2007, 318 (5854), 1305-1308.

Foster, Andrew D. and Mark R. Rosenzweig, "Learning by Doing and Learning from Others: Human Capital and Technical Change in Agriculture," Journal of Political Economy, December 1995, 103 (6), 1176-1209. 
Frey, Bruno S. and Stephen Meier, "Social Comparisons and Pro-social Behavior: Testing "Conditional Cooperation" in a Field Experiment," American Economic Review, December 2004, 94 (5), 1717-1722.

Gali, Jordi, "Keeping Up with the Joneses: Consumption Externalities, Portfolio Choice, and Asset Prices," Journal of Money, Credit and Banking, 1994, 26 (1), 1-8.

Grinblatt, Mark, Matti Keloharju, and Seppo Ikaheimo, "Social Influence and Consumption: Evidence from the Automobile Purchases of Neighbors," Review of Economics and Statistics, November 2008, 90 (4), 735-753.

Guarino, Antonio and Philippe Jehiel, "Social Learning with Coarse Inference," American Economic Journal: Microeconomics, forthcoming.

Guryan, Jonathan, Kory Kroft, and Matthew J. Notowidigdo, "Peer Effects in the Workplace: Evidence from Random Groupings in Professional Golf Tournaments," American Economic Journal: Applied Economics, 2009, 1 (4), 34-68.

Harrison, Glenn W. and John A. List, "Field Experiments," Journal of Economic Literature, December 2004, 42 (4), 1009-1055.

Hirshleifer, David and Siew Hong Teoh, "Herd Behaviour and Cascading in Capital Markets: a Review and Synthesis," European Financial Management, March 2003, 9 (1), 25-66.

Hong, Harrison, Jeffrey D. Kubik, and Jeremy Stein, "Social Interaction and Stock-market Participation," Journal of Finance, February 2004, 59 (1), 137-163.

_, Jeffrey Kubik, and Jeremy Stein, "Thy Neighbor's Portfolio: Word-of-Mouth Effects in the Holdings and Trades of Money Managers," The Journal of Finance, 2005, 60, 2801-2824.

Hung, Angela A., Noreen Clancy, Jeff Dominitz, Eric Talley, Claude Berrebi, and Farrukh Suvankulov, "Investor and Industry Perspectives on Investment Advisers and BrokerDealers," 2008. RAND Institute for Civil Justice Technical Report. 
Instefjord, Norvald, Jerry Coakley, and Zhe Shen, "The Winner's Curse and LotteryAllocated IPOs in China," February 2007. University of Essex Working Paper.

Ivkovic, Zoran and Scott Weisbenner, "Information Diffusion Effects in Individual Investors' Common Stock Purchases: Covet Thy Neighbors' Investment Choices," Review of Financial Studies, 2007, 20 (4), 1327-1357.

Kling, Jeffrey R., Jeffrey B. Liebman, and Lawrence F. Katz, "Experimental Analysis of Neighborhood Effects," Econometrica, 2007, 75, 83-119.

Kremer, Michael and Edward Miguel, "The Illusion of Sustainability," Quarterly Journal of Economics, August 2007, 122 (3), 1007-1065.

Kuhn, Peter, Peter Kooreman, Adriaan Soetevent, and Arie Kapteyn, "The Effects of Lottery Prizes on Winners and Their Neighbors: Evidence from the Dutch Postcode Lottery," American Economic Review, August 2011, 101 (5), 2226-2247.

Li, Geng, "Information Sharing and Stock Market Participation: Evidence from Extended Families," 2009. Board of Governors of the Federal Reserve System, Finance and Economics Discussion Series, 2009-47.

Lusardi, Annamaria and Olivia S. Mitchell, "Financial literacy and retirement planning in the United States," Journal of Pension Economics and Finance, September 2011, 10 (4), 509-525.

_ and _, "Financial literacy around the world: an overview," Journal of Pension Economics and Finance, September 2011, 10 (4), 497-508.

Luttmer, Erzo F. P., "Neighbors as Negatives: Relative Earnings and Well-Being," Quarterly Journal of Economics, 2005, 120 (3), 963-1002.

Maertens, Annemie, "Who Cares What Others Think (or Do)? Social Learning, Social Pressures and Imitation in Cotton Farming in India," February 2012. University of Pittsburgh Working Paper. 
Manski, Charles F., "Identification of Endogenous Social Effects: The Reflection Problem," Review of Economic Studies, 1993, 60 (3), 531-542.

Mas, Alexandre and Enrico Moretti, "Peers at Work," American Economic Review, 2009, 99 (1), 112-145.

Moretti, Enrico, "Social Learning and Peer Effects in Consumption: Evidence from Movie Sales," Review of Economic Studies, 2011, 78 (1), 356-393.

Moscarini, Giuseppe, Marco Ottaviani, and Lones Smith, "Social Learning in a Changing World," Economic Theory, May 1998, 11 (3), 657-665.

Sacerdote, Bruce, "Peer Effects with Random Assignment: Results for Dartmouth Roommates," Quarterly Journal of Economics, May 2001, 116 (2), 681-704.

Shue, Kelly, "Executive Networks and Firm Policies: Evidence from the Random Assignment of MBA Peers," April 2012. University of Chicago, Booth School of Business.

Sorensen, Alan T., "Social Learning and Health Plan Choice," RAND Journal of Economics, Winter 2006, $37(4), 929-945$.

Taylor, Chris, "Tight Budgets, Wild Markets Hurt Investment Clubs," December 2011. 


\section{Figures and Tables}

\section{Figure 1: Experimental design "roadmap"}

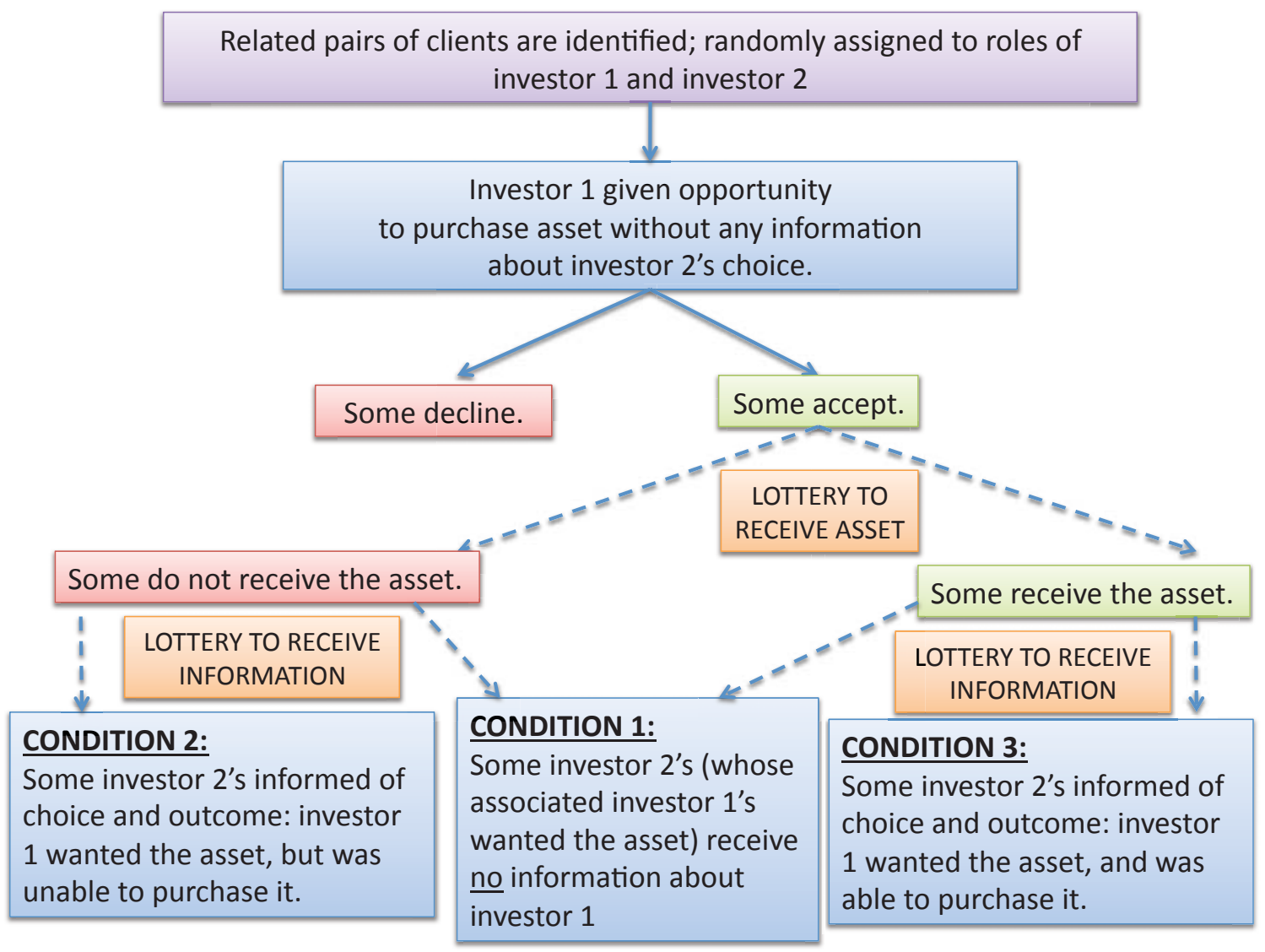




\section{Figure 2: Investor 2's take-up rates}

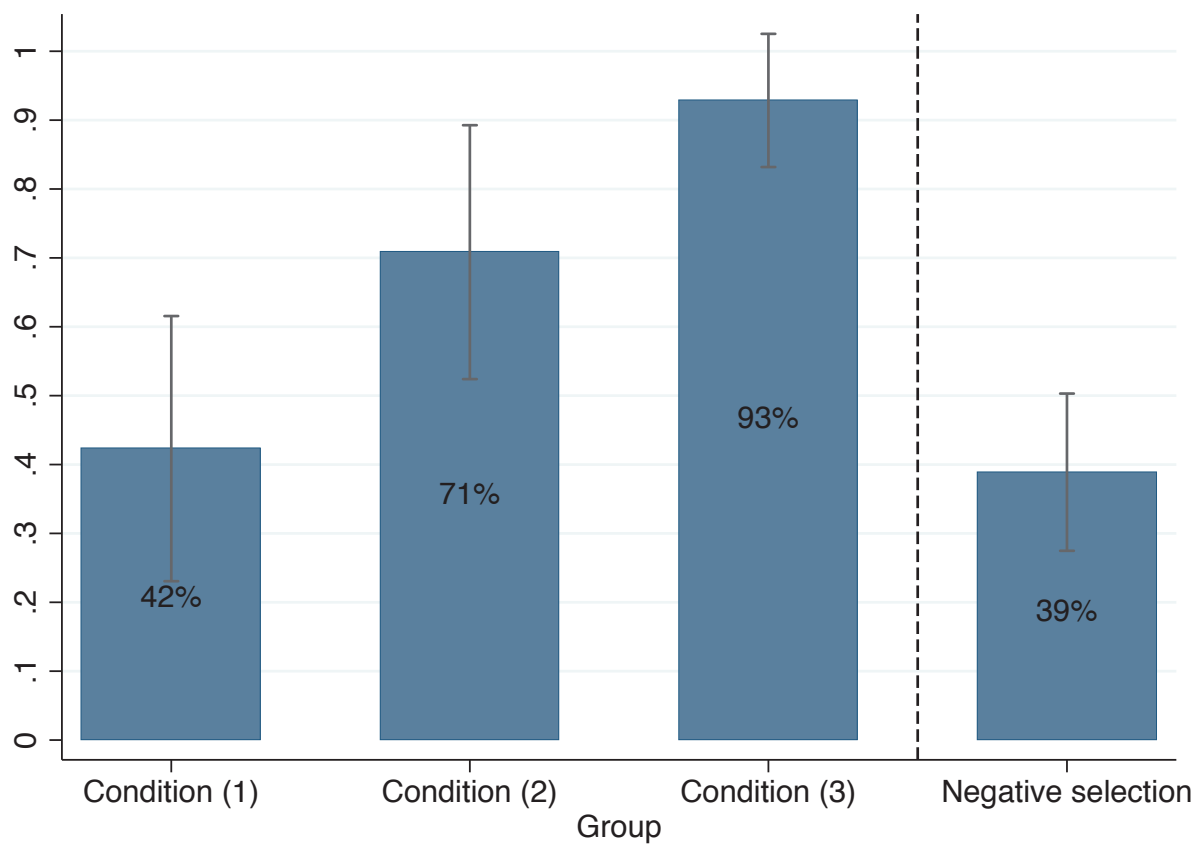

Note: This figure presents the mean (and 95\% confidence interval) of the take-up rate for each group of investor 2's. Investors in conditions (1) to (3) have peers who wanted the asset. These investors were randomly allocated to one of these 3 groups. Those in condition (1) had no information about their peers. Those in condition (2) had information that their peers wanted to purchase the asset but had that choice rejected by the lottery. Those in condition (3) had information that their peers wanted and received the asset. Investors in the negative selection group have peers who did not want to purchase the asset (and received no information about their peer). 
Table 1: Characteristics of the Experimental Sample

\begin{tabular}{|c|c|c|c|c|c|c|c|c|}
\hline & \multicolumn{7}{|c|}{ Experimental Sample } & \multirow{4}{*}{$\begin{array}{c}\text { Universe } \\
\text { (8) }\end{array}$} \\
\hline & \multirow{3}{*}{$\begin{array}{c}\text { Full } \\
\text { Sample } \\
(1)\end{array}$} & \multicolumn{3}{|c|}{ Investor 1} & \multicolumn{3}{|c|}{ Investor 2} & \\
\hline & & \multirow{2}{*}{$\begin{array}{l}\text { All } \\
(2)\end{array}$} & \multicolumn{2}{|c|}{ Wanted the asset? } & \multirow{2}{*}{$\begin{array}{l}\text { All } \\
\text { (5) }\end{array}$} & \multicolumn{2}{|c|}{ Peer wanted the asset? } & \\
\hline & & & $\begin{array}{l}\text { Yes } \\
(3)\end{array}$ & $\begin{array}{l}\text { No } \\
(4)\end{array}$ & & $\begin{array}{l}\text { Yes } \\
(6)\end{array}$ & $\begin{array}{l}\text { No } \\
(7)\end{array}$ & \\
\hline Age & $\begin{array}{l}38.15 \\
(0.80)\end{array}$ & $\begin{array}{l}39.12 \\
(1.14)\end{array}$ & $\begin{array}{l}39.60 \\
(1.60)\end{array}$ & $\begin{array}{l}38.60 \\
(1.62)\end{array}$ & $\begin{array}{l}37.18 \\
(1.12)\end{array}$ & $\begin{array}{l}36.45 \\
(1.50)\end{array}$ & $\begin{array}{l}37.97 \\
(1.68)\end{array}$ & $\begin{array}{l}34.14 \\
(0.16)\end{array}$ \\
\hline $\begin{array}{l}\text { Gender } \\
(=1 \text { If male })\end{array}$ & $\begin{array}{c}0.680 \\
(0.027)\end{array}$ & $\begin{array}{c}0.747 \\
(0.036)\end{array}$ & $\begin{array}{c}0.769 \\
(0.048)\end{array}$ & $\begin{array}{c}0.722 \\
(0.053)\end{array}$ & $\begin{array}{c}0.613 \\
(0.040)\end{array}$ & $\begin{array}{c}0.641 \\
(0.055)\end{array}$ & $\begin{array}{c}0.583 \\
(0.059)\end{array}$ & $\begin{array}{c}0.729 \\
(0.006)\end{array}$ \\
\hline Married & $\begin{array}{c}0.413 \\
(0.028)\end{array}$ & $\begin{array}{c}0.440 \\
(0.041)\end{array}$ & $\begin{array}{c}0.436 \\
(0.057)\end{array}$ & $\begin{array}{c}0.444 \\
(0.059)\end{array}$ & $\begin{array}{c}0.387 \\
(0.040)\end{array}$ & $\begin{array}{c}0.333 \\
(0.054)\end{array}$ & $\begin{array}{c}0.444 \\
(0.059)\end{array}$ & $\begin{array}{c}0.340 \\
(0.006)\end{array}$ \\
\hline Single & $\begin{array}{c}0.557 \\
(0.029)\end{array}$ & $\begin{array}{c}0.527 \\
(0.041)\end{array}$ & $\begin{array}{c}0.513 \\
(0.057)\end{array}$ & $\begin{array}{c}0.542 \\
(0.059)\end{array}$ & $\begin{array}{c}0.587 \\
(0.040)\end{array}$ & $\begin{array}{c}0.628 \\
(0.055)\end{array}$ & $\begin{array}{c}0.542 \\
(0.059)\end{array}$ & $\begin{array}{c}0.647 \\
(0.006)\end{array}$ \\
\hline Earnings & $\begin{array}{l}4,500 \\
(256)\end{array}$ & $\begin{array}{l}5,000 \\
(499)\end{array}$ & $\begin{array}{l}5,000 \\
(501)\end{array}$ & $\begin{array}{l}5,000 \\
(775)\end{array}$ & $\begin{array}{l}4,000 \\
(507)\end{array}$ & $\begin{array}{l}4,000 \\
(504)\end{array}$ & $\begin{array}{l}3,500 \\
(650)\end{array}$ & $\begin{array}{l}3,200 \\
(126)\end{array}$ \\
\hline $\begin{array}{l}\text { Relationship } \\
\text { with associated } \\
\text { investor } \\
(=1 \text { if family })\end{array}$ & $\begin{array}{c}0.48 \\
(0.03)\end{array}$ & $\begin{array}{l}0.48 \\
(0.04)\end{array}$ & $\begin{array}{c}0.53 \\
(0.06)\end{array}$ & $\begin{array}{c}0.43 \\
(0.06)\end{array}$ & $\begin{array}{c}0.48 \\
(0.04)\end{array}$ & $\begin{array}{c}0.53 \\
(0.06)\end{array}$ & $\begin{array}{c}0.43 \\
(0.06)\end{array}$ & - \\
\hline $\mathrm{N}$ & 300 & 150 & 78 & 72 & 150 & 78 & 72 & 5506 \\
\hline
\end{tabular}

Notes: Column 1 presents the characteristics of the experimental sample, combining investor 1's and investor 2's. Column 2 presents the sample characteristics of investor 1's in the experimental sample, while columns 3 and 4 present the information for investor 1's who wanted and who did not want the asset, respectively. Column 5 presents the characteristics of investors 2's in the experimental sample, while columns 6 and 7 present the information for investor 2's whose peers wanted and did not want the asset, respectively. Column 8 presents the characteristics of the universe of investors in the main office of the brokerage. Each line presents averages of the corresponding variable. For earnings, we present the median value instead of the mean due to large outliers. The sample size for the earnings variable is smaller due to missing values. The omitted value for "Relationship with associated investor" is "friends". This variable is not defined for investors outside the experiment's sample. 


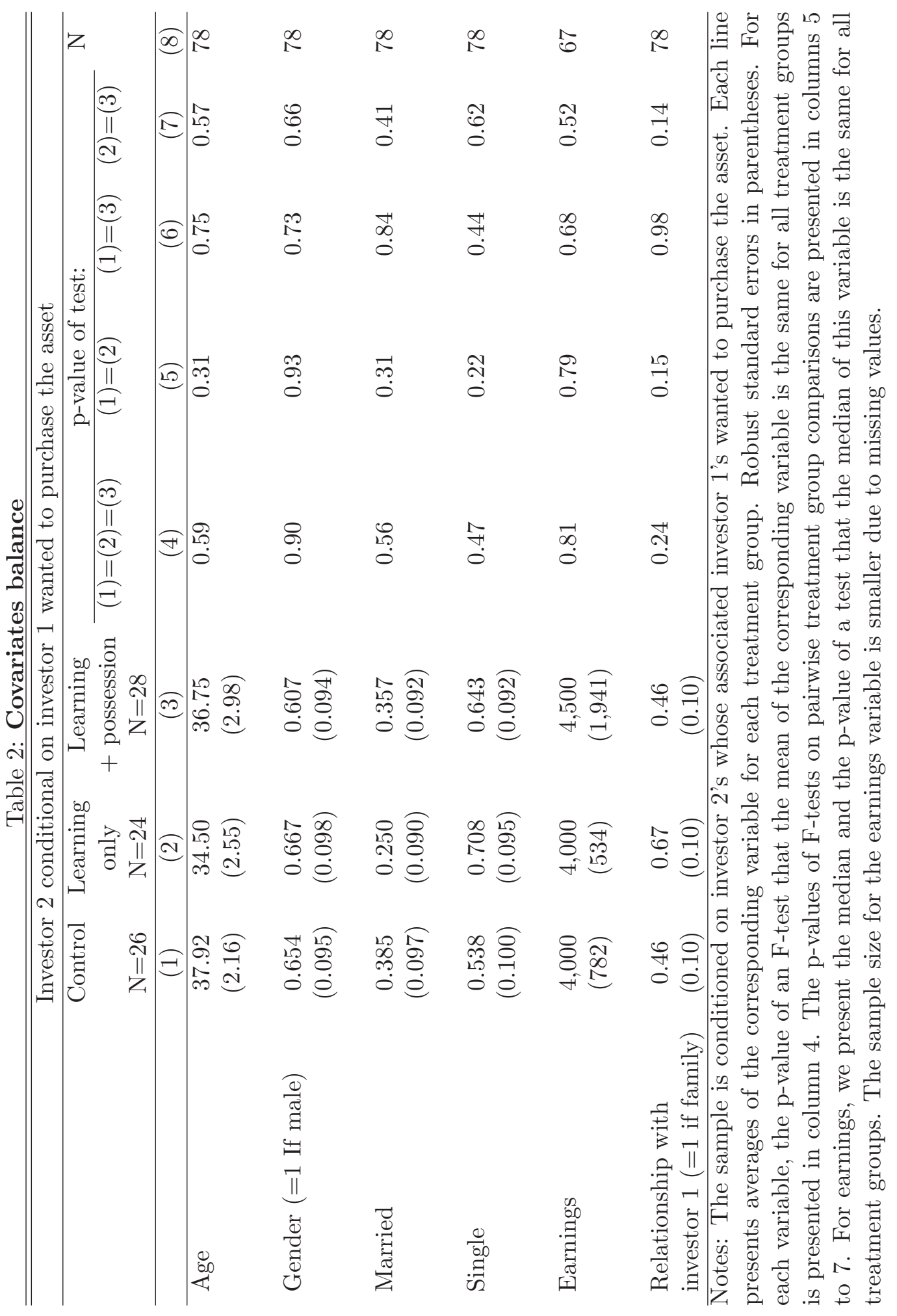


Table 3: Peer Effects, Social Learning, Social Utility, and Selection: Take-up Rates

\begin{tabular}{|c|c|c|c|c|}
\hline Dependent variable & \multicolumn{4}{|c|}{ Wanted to purchase the asset } \\
\hline & (1) & $(2)$ & $(3)$ & (4) \\
\hline $\begin{array}{l}\text { Learning alone } \\
\text { (Condition (2) - Condition (1)) }\end{array}$ & $\begin{array}{c}0.285^{* *} \\
(0.136)\end{array}$ & $\begin{array}{c}0.298^{* *} \\
(0.140)\end{array}$ & $\begin{array}{c}0.328^{* *} \\
(0.134)\end{array}$ & $\begin{array}{c}0.278^{* *} \\
(0.127)\end{array}$ \\
\hline $\begin{array}{l}\text { Learning and possession } \\
\text { (Condition }(3) \text { - Condition (1)) }\end{array}$ & $\begin{array}{c}0.505^{* * *} \\
(0.110)\end{array}$ & $\begin{array}{c}0.540^{* * *} \\
(0.122)\end{array}$ & $\begin{array}{c}0.552^{* * *} \\
(0.123)\end{array}$ & $\begin{array}{c}0.500^{* * *} \\
(0.111)\end{array}$ \\
\hline Negative selection & $\begin{array}{l}-0.034 \\
(0.114)\end{array}$ & $\begin{array}{c}0.011 \\
(0.124)\end{array}$ & $\begin{array}{l}-0.005 \\
(0.118)\end{array}$ & $\begin{array}{c}0.042 \\
(0.117)\end{array}$ \\
\hline Investor 1 & & & & $\begin{array}{c}0.128 \\
(0.106)\end{array}$ \\
\hline $\begin{array}{l}\text { Possession alone } \\
\text { (Condition (3) - Condition (2)) }\end{array}$ & $\begin{array}{l}0.220^{* *} \\
(0.106)\end{array}$ & $\begin{array}{c}0.242^{* *} \\
(0.109)\end{array}$ & $\begin{array}{l}0.224^{*} \\
(0.124)\end{array}$ & $\begin{array}{c}0.222^{* *} \\
(0.108)\end{array}$ \\
\hline $\begin{array}{l}\text { Mean (no information; peer chose the asset) } \\
\text { (Condition (1)) }\end{array}$ & & & & \\
\hline Broker fixed effects & No & Yes & Yes & Yes \\
\hline Controls & No & No & Yes & Yes \\
\hline $\mathrm{N}$ & 150 & 150 & 150 & 300 \\
\hline$R^{2}$ & 0.186 & 0.228 & 0.283 & 0.219 \\
\hline
\end{tabular}

Notes: Column 1 presents the results of a regression of a dummy variable equal to one if the investor wanted to purchase the asset on a dummy for condition (3), a dummy for condition (2), and a dummy indicating whether the associated investor 1 did not want to purchase the asset ("Negative selection"). Investor 2's in condition (1) is the omitted group. This regression uses only the sample of investor 2's. The regression presented in column 2 includes broker fixed effects. The regression presented in column 3 includes the covariates presented in Table 2. We did not include earnings as this would reduce our sample size (results including earnings are similar). The regression presented in column 4 combines the sample of investors 1 and 2, and includes an indicator variable for investor 1 . Standard errors are clustered at the pair level. In all columns, "Possession alone" gives the difference between the coefficient on "Learning and possession" and the coefficient on "Learning alone." * significant at $10 \%$; ** significant at $5 \%$; ** significant at $1 \%$. 
Table 4: Peer Effects, Social Learning, Social Utility, and Selection: Alternative Outcomes

\begin{tabular}{|c|c|c|c|c|}
\hline \multirow[t]{2}{*}{ Dependent variable } & \multicolumn{2}{|c|}{ Amount invested } & \multicolumn{2}{|c|}{ Invested more than minimum } \\
\hline & $(1)$ & $(2)$ & $(3)$ & $(4)$ \\
\hline $\begin{array}{l}\text { Learning alone } \\
\text { (Condition (2) - Condition (1)) }\end{array}$ & $\begin{array}{c}948.7^{* * *} \\
(357.7)\end{array}$ & $\begin{array}{l}715.2^{*} \\
(394.5)\end{array}$ & $\begin{array}{c}0.212^{* *} \\
(0.097)\end{array}$ & $\begin{array}{l}0.173^{*} \\
(0.095)\end{array}$ \\
\hline $\begin{array}{l}\text { Learning and possession } \\
\text { (Condition (3) - Condition (1)) }\end{array}$ & $\begin{array}{l}2,633.2^{* * *} \\
(702.9)\end{array}$ & $\begin{array}{l}2,521.4^{* * *} \\
(611.9)\end{array}$ & $\begin{array}{c}0.497^{* * *} \\
(0.103)\end{array}$ & $\begin{array}{c}0.485^{* * *} \\
(0.101)\end{array}$ \\
\hline Negative selection & $\begin{array}{l}-106.8 \\
(239.0)\end{array}$ & $\begin{array}{c}123.9 \\
(308.6)\end{array}$ & $\begin{array}{l}-0.038 \\
(0.038)\end{array}$ & $\begin{array}{l}-0.016 \\
(0.049)\end{array}$ \\
\hline Investor 1 & & $\begin{array}{l}503.8^{*} \\
(300.1)\end{array}$ & & $\begin{array}{l}0.097^{*} \\
(0.053)\end{array}$ \\
\hline $\begin{array}{l}\text { Possession alone } \\
\text { (Condition (3) - Condition (2)) }\end{array}$ & $\begin{array}{c}1,684.5^{* *} \\
(731.4)\end{array}$ & $\begin{array}{l}1,806.1^{* *} \\
(727.0)\end{array}$ & $\begin{array}{c}0.286^{* *} \\
(0.131)\end{array}$ & $\begin{array}{c}0.311^{* *} \\
(0.128)\end{array}$ \\
\hline $\begin{array}{l}\text { Mean (no information; peer chose the asset) } \\
\text { (Condition (1)) }\end{array}$ & & & $\begin{array}{c}0.038 \\
(0.038)\end{array}$ & \\
\hline Broker fixed effects & No & Yes & No & Yes \\
\hline Controls & No & Yes & No & Yes \\
\hline $\mathrm{N}$ & 150 & 300 & 150 & 300 \\
\hline $\mathrm{R} 2$ & 0.251 & 0.264 & 0.338 & 0.295 \\
\hline
\end{tabular}

Notes: Columns 1 and 2 replicate the regressions in columns 1 and 4 of Table 3 using the amount invested in the asset instead of take-up rate as dependent variable. Columns 3 and 4 replicate the regressions in columns 1 and 4 of Table 3 using a dummy variable equal to one if the investor invested more than the minimum amount as dependent variable. ${ }^{*}$ significant at $10 \% ; * *$ significant at $5 \%$; ** significant at $1 \%$. 


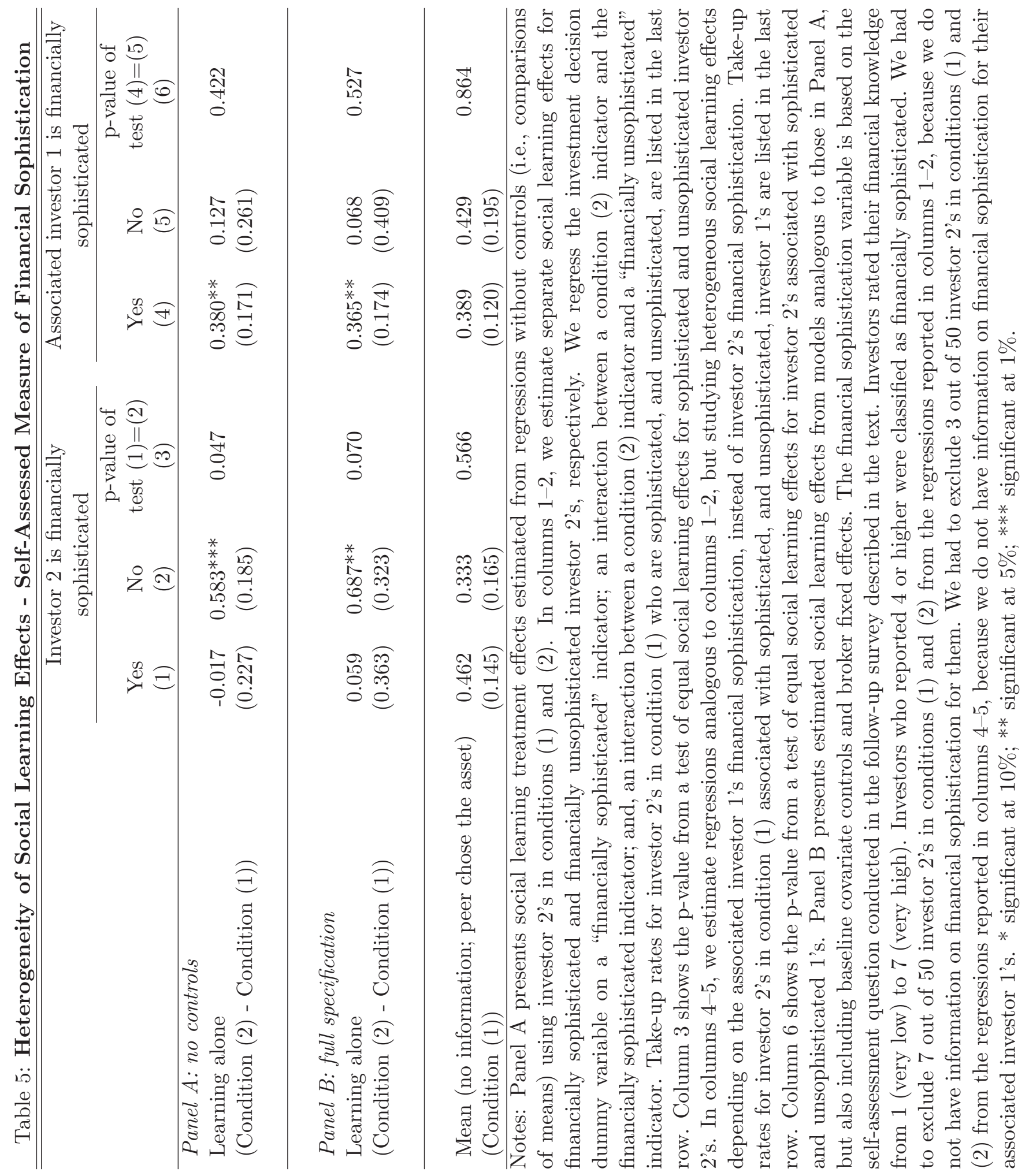


Table 6: Robustness Tests

\begin{tabular}{lcc}
\hline \hline $\begin{array}{l}\text { Interaction of the } \\
\text { treatment effects with: }\end{array}$ & $\begin{array}{c}\text { Relationship with } \\
\text { investor } 1(=1 \text { if family })\end{array}$ & $\begin{array}{c}\text { Broker experience } \\
\text { within }\end{array}$ \\
& 0.077 & $(2)$ \\
\hline Learning alone & $(0.305)$ & -0.001 \\
& $0.417^{*}$ & $(0.008)$ \\
Learning and possession & $(0.232)$ & -0.003 \\
& & $(0.008)$ \\
\hline \multirow{2}{*}{ Possession alone } & 0.340 & -0.001 \\
& $(0.220)$ & $(0.007)$ \\
\hline
\end{tabular}

Notes: This table presents coefficients on the interactions of the variables at the column heading with the treatment effects of interest. These results are based on the regressions used in the full specification of column 4 from Table 3, including interactions of the group dummies $\left(I_{c, i}\right.$, where $c \in$ \{condition (2), condition (3), "negative selection", investor 1\}) with the corresponding variables. We also include the main effect of the corresponding variable. In column 1, we interact the treatment effects with a dummy variable equal to one if the investors 1 and 2 are family members. The omitted category is "friends". In column 2 , we interact the treatment effects with a variable indicating the number of calls that the broker had made before the day of the call. ${ }^{*}$ significant at $10 \% ; * *$ significant at $5 \% ; * * *$ significant at $1 \%$. 


\section{ONLINE APPENDIX}

(NOT FOR PUBLICATION)

\section{Appendix A: A Simple Model of Financial Decisions Under Social}

\section{Influence}

Our model studies an investment decision made by an individual under several conditions. First, we present the investment decision under uncertainty, but with no social influence. Second, we present the investment decision with social learning present, using the ingredients of a canonical social learning model: a peer makes an investment acting on a private signal, and this action can be used by another investor to make an informational inference before taking his own action. Third, we allow the ownership of an asset to affect a socially-related investor's utility of owning the asset, aside from any learning - that is, we allow for a social utility effect. A peer's purchase decision typically will produce both social learning and social utility effects; we consider a case in which both effects are active (the full "peer effect") and a case in which the revealed preference purchase decision is de-coupled from possession. This de-coupling allows one to observe each channel through which peer effects work, and motivates our experimental design.

\section{Investment without Peer Effects}

Consider an investor $i$ 's decision to invest in a risky asset. ${ }^{43}$ The asset's return is given by $x$, with probability density function $f(x)$, and investor $i$ 's utility is $u_{i}(x)=u(x)$ for all $i$. In our field experiment, investors received calls from brokers who offered them a financial asset for purchase. The brokers attempted to convey the same information about the asset in every call using a prespecified script; thus, the information they provided can be thought of as a signal, $s_{i}$, coming from a single distribution, with probability density function $g\left(s_{i}\right)$. Importantly, not every investor would have received exactly the same information: calls evolve in different ways, investors ask different

\footnotetext{
${ }^{43}$ Note that we implicitly assume that when investing in isolation, investor $i$ does not take into consideration any investor $j(j \neq i)$ at all - he is "unaware." In the context of our experiment, we believe that this assumption is reasonable, as we discuss in the text.
} 
questions about the asset, etc., meaning that each investor received a different signal realization, $s_{i}$, from the common distribution of signals.

For expositional simplicity, assume that the conditional density $f\left(x \mid s_{i}\right)$ satisfies the monotone likelihood ratio property (MLRP) such that, intuitively, higher values of $s_{i}$ are indicative of higher values of $x$. Under these conditions, investor $i$ is willing to invest if and only if

$$
\int u(x) f\left(x \mid s_{i}\right) d x \geq \bar{u}
$$

where $\bar{u}$ denotes the outside option of the investor. Given that $f\left(x \mid s_{i}\right)$ satisfies MLRP and given mild monotonicity assumptions on the utility function $u(\cdot)$ of the investor, there exists a unique threshold $\bar{s}_{1}$ such that for any $s_{i} \geq \bar{s}_{1}$ investor $i$ is willing to invest. Denote the decision to buy the asset made by investor $i$ by $b_{i}=\{0,1\}$. Hence, for an investor making a purchase decision in isolation, we have

$$
b_{i}=1 \Leftrightarrow s_{i} \geq \bar{s}_{1}
$$

\section{Investment with Social Learning Alone}

Suppose that instead of making his investment choice in isolation, before making his own decision, investor $i$ observes the investment decision of investor $j$ which is given by $b_{j}$. Assume that investor $j$ made his choice $b_{j}=1$ in isolation and hence his decision rule is given by (3). ${ }^{44}$ Thus, when investor $i$ observes $b_{j}=1$ he correctly infers that $s_{j} \geq \bar{s}_{1}$ and he is willing to invest if and only if

$$
\int u(x) f\left(x \mid s_{i} ; s_{j} \geq \bar{s}_{1}\right) d x \geq \bar{u}
$$

Furthermore, given that $f\left(x \mid s_{i} ; s_{j}\right)$ satisfies MLRP we have

$$
\int u(x) f\left(x \mid s_{i} ; s_{j} \geq \bar{s}_{1}\right) d x \geq \int u(x) f\left(x \mid s_{i}\right) d x,
$$

\footnotetext{
${ }^{44}$ We focus on the case of investor $i$ observing that investor $j$ chose to purchase the asset (rather than choosing not to purchase it) because in the experimental design, we were not allowed to inform investors that their peer chose not to purchase the asset.
} 
for all $s_{i}$. It is straightforward to show by comparing (4) and (2) that the signal realization threshold for investor $i$ that is necessary to induce purchase of the asset is lower when $b_{j}=1$ is observed than when investor $i$ makes his choice in isolation. This is because in the former case, regardless of his own private information summarized by $s_{i}$, investor $i$ has additional favorable information about the asset from observing the purchase of investor $j$. This is the pure social learning effect.

Denote the threshold for $s_{i}$ when investor $i$ observes $b_{j}=1$ by $\bar{s}_{2}$ and note that $\bar{s}_{2} \leq \bar{s}_{1}$. In particular, after observing a purchase decision made by investor $j$, the decision rule of investor $i$ is given by

$$
b_{i}=1 \Leftrightarrow s_{i} \geq \bar{s}_{2}
$$

\section{Social Utility and Social Learning}

We now consider the situation in which both social utility and social learning effects are present. Our focus (following much of the literature on peer effects in financial decisions) is on social utility effects that result in a positive effect of a peer's possession of an asset (denoted by $p_{j}=\{0,1\}$ ) on one's own utility. ${ }^{45}$ In particular, when investor $i$ considers purchasing the asset, we assume that $u\left(x \mid p_{j}=1\right) \geq u\left(x \mid p_{j}=0\right)$ for all $x$. That is, investor $i$ 's utility is higher for all asset return realizations if the asset is also possessed by an investor $j$ who is a peer of investor $i$. Using the notation of our model, an investor $j$ 's purchase of an asset, $b_{j}=1$, typically implies both that investor $i$ infers favorable information about the asset, $s_{j} \geq \bar{s}_{1}$, and that investor $j$ now possesses the asset, $p_{j}=1$, which might affect investor $i$ 's utility of owning the asset (due to a taste for joint consumption, "keeping-up-with-the-Joneses" preferences).

When investor $i$ observes that investor $j$ expressed an intention to invest, $b_{j}=1$, and was allowed to invest, $p_{j}=1$, both investor $i$ 's utility $u\left(x \mid p_{j}=1\right)$ and his information about the asset $f\left(x \mid s_{i} ; s_{j} \geq \bar{s}_{1}\right)$ are affected, relative to his choice in isolation (that is, relative to $u(x)=u\left(x \mid p_{j}=0\right)$

\footnotetext{
${ }^{45}$ One could also imagine a negative correlation, for example, out of a desire to insure one's peers, or to differentiate oneself. See Clark and Oswald (1998).
} 
and $\left.f\left(x \mid s_{i}\right)\right) .{ }^{46}$ In this case, one observes the "full" peer effect, and investor $i$ invests if and only if

$$
\int u\left(x \mid p_{j}=1\right) f\left(x \mid s_{i} ; s_{j} \geq \bar{s}_{1}\right) d x \geq \bar{u} .
$$

Denote the threshold for $s_{i}$ above which investor $i$ is willing to invest when exposed to both peer effects channels by $\bar{s}_{3}$. Then, the decision rule for investor $i$ is given by

$$
b_{i}=1 \Leftrightarrow s_{i} \geq \bar{s}_{3}
$$

To separate the effects of social learning and social utility, we need to decouple willingness to purchase (and the informative signal of the purchase decision) from possession. Consider the situation where investor $i$ observes that investor $j$ expressed a revealed preference to invest, but was not allowed to do so (perhaps due to capacity constraints). In this case, investor $i$ infers that $s_{j} \geq \bar{s}_{1}$, but also knows that investor $j$ did not obtain the asset, so $p_{j}=0$. This condition is equivalent to the "social learning alone" problem discussed above: there is no direct effect of possession on investor $i$ 's utility from the asset, but there is social learning. Thus, investor $i$ purchases the asset if and only if (4) is satisfied ( (6) with the threshold $\bar{s}_{2}$.

The following proposition summarizes investor $i$ 's purchase decisions across conditions.

Proposition 1. The threshold for the signal $s_{i}$ above which investor $i$ is willing to purchase the asset (and, the likelihood of a purchase of the asset by investor i) is highest (lowest) when the investor makes his decision in isolation, lower (higher) when he observes that investor $j$ intended to purchase the asset but did not obtain it, and lowest (highest) when investor $j$ intended to purchase the asset, and obtained it: $\bar{s}_{1} \geq \bar{s}_{2} \geq \bar{s}_{3}\left(\right.$ and $\left.\operatorname{Pr}\left(s_{i} \geq \bar{s}_{3}\right) \geq \operatorname{Pr}\left(s_{i} \geq \bar{s}_{2}\right) \geq \operatorname{Pr}\left(s_{i} \geq \bar{s}_{1}\right)\right)$.

Proof. The relationship between $\bar{s}_{1}$ and $\bar{s}_{2}$ follows immediately from comparing the inequalities (2) and (4) and the monotone likelihood ratio property of $f\left(x \mid s_{i} ; s_{j}\right)$. Similarly, comparison of the inequalities (4) and (7) and $u(x)=u\left(x \mid p_{j}=0\right) \leq u\left(x \mid p_{j}=1\right)$ establishes that $\bar{s}_{2} \geq \bar{s}_{3}$. Finally,

\footnotetext{
${ }^{46}$ We are assuming here that the utility function discussed above, $u(x)$, is the same as $u\left(x \mid p_{j}=0\right)$ here. In addition, we are assuming that investor $j$ made his decision in isolation.
} 
$\operatorname{Pr}\left(s_{i} \geq \bar{s}_{3}\right) \geq \operatorname{Pr}\left(s_{i} \geq \bar{s}_{2}\right) \geq \operatorname{Pr}\left(s_{i} \geq \bar{s}_{1}\right)$ follows from the ranking of the thresholds.

The difference between $\overline{s_{2}}$ and $\overline{s_{3}}$ is the result of a difference in investor $j$ 's possession of the asset. $^{47}$ In one situation investor $j$ received favorable information and expressed an intent to purchase the asset, but was unable to execute the purchase due to supply restrictions. In the other situation investor $j$ received a favorable signal and was also able to obtain the asset. Thus, in the two cases investor $i$ infers the same information (via investor $j$ 's choice) about the potential returns of asset $x$. However, only in the latter case is investor $i$ 's utility directly influenced by the investment outcome (and not just the purchase intention) of investor $j$. This is the social utility effect that raises the expected utility of purchasing the asset for investor $i$ over and above the social learning effect. In the inequalities in Proposition 1, the effect of social learning is captured by the difference between $\operatorname{Pr}\left(s_{i} \geq \bar{s}_{2}\right)$ and $\operatorname{Pr}\left(s_{i} \geq \bar{s}_{1}\right)$, and the effect of social utility is the difference between $\operatorname{Pr}\left(s_{i} \geq \bar{s}_{3}\right)$ and $\operatorname{Pr}\left(s_{i} \geq \bar{s}_{2}\right)$. The total peer effect is the difference between $\operatorname{Pr}\left(s_{i} \geq \bar{s}_{3}\right)$ and $\operatorname{Pr}\left(s_{i} \geq \bar{s}_{1}\right)$.

Our analysis readily extends to the case in which investor $i$ 's investment choice is continuous rather than limited to a binary decision. In particular, since $f\left(x \mid s_{i} ; s_{j}\right)$ satisfies MLRP, the optimal investment in the asset is increasing in $s_{i}$ and $s_{j}$ and the expected equilibrium investment amounts will follow exactly the prediction regarding purchase rates in Proposition 1. Suppose individual $i$ chooses an investment magnitude $q_{i}^{*}$, rather than making a binary investment decision. Since $f\left(x \mid s_{i} ; s_{j}\right)$ satisfies MLRP, the optimal investment in the asset is increasing in $s_{i}$ and $s_{j}$ and we can rank the expected equilibrium investment amounts.

Proposition 2. The expected equilibrium investment amount $q_{i}^{*}$ of investor $i$ is lowest when the investor makes his decision in isolation, higher when he observes that investor $j$ intended to purchase the asset but did not obtain it, and highest when investor $j$ intended to purchase, and obtained, the asset.

\footnotetext{
${ }^{47}$ Note that the difference between $\overline{s_{2}}$ and $\overline{s_{3}}$ measures the impact of possession conditional on the presence of social learning. This is consistent with our experimental design, in which we are not able to measure the impact of possession in the absence of social learning.
} 
Proof. The inference problem of investor $i$ is the same as in Proposition 1. Thus, for a given signal $s_{i}$ the described relationship holds for the actual equilibrium investment amount and follows immediately from comparing the expression for the utilities on the left-hand side of the inequalities (2), (4) and (7) and by noting that the optimal investment amount is increasing in $s_{i}$ and $s_{j}$. Finally, taking expectations over the signal realizations $s_{i}$ yields the ranking in expected investment amounts.

\section{Heterogeneous Investors}

In practice, some investors are more financially sophisticated than others, and one would expect that this variation will affect the peer effects we study here - especially the impact of social learning. In particular, an unsophisticated investor may have much more to learn about an asset from the purchase decision of their peer than does a sophisticated investor, as the sophisticated investor likely has a very good sense of the asset's quality from his signal alone. Differing financial sophistication can be captured in our model by allowing the signals $s_{i}$ and $s_{j}$ to be drawn from distributions with differing precision. For simplicity, we make the assumption that, in contrast to unsophisticated investors, sophisticated investors receive perfectly informative signals. This assumption generates the following prediction of heterogeneous effects of social learning.

Proposition 3. The thresholds $\bar{s}_{1}$ and $\bar{s}_{2}$ for the signal $s_{i}$ above which investor $i$ is willing to purchase the asset (and hence the likelihood of investor $i$ purchasing the asset) are identical if investor $i$ is financially sophisticated (i.e., signal $s_{i}$ is perfectly informative). If investor $j$ is sophisticated, then investor $i$ follows the choice of investor $j$ when observing the decision of investor $j$.

Proof. If $s_{i}$ is perfectly informative (i.e., investor $i$ is sophisticated), then $s_{i}$ is a sufficient statistic for $x$. As a result, $s_{j}$, and hence the purchase decision of investor $j$, has no informational value for sophisticated investor $i$ and does not influence the threshold $\bar{s}_{1}$. Hence, $\bar{s}_{1}=\bar{s}_{2}$. If $s_{j}$ is perfectly informative, then investor $j$ knows the value of $x$ and makes a perfectly informed investment decision. As a result, investor $i$ follows investor $j$ 's choice. 
Proposition 3 suggests that social learning will be limited (in fact, given the simplifying assumptions made, will be nonexistent) for sophisticated investors. These investors are sufficiently well-informed that they are not influenced by the revealed preference of another investor. The proposition further shows that social learning will have relatively strong effects on investment choices if the investor whose choice is observed is sophisticated. ${ }^{48}$

\footnotetext{
${ }^{48}$ We have assumed that sophisticated investors receive perfectly informative signals. Our results can be extended to the case in which sophisticated investors receive more informative, but still imperfectly informative, signals. While results for general distributions of $x, s_{i}$ and $s_{j}$ that satisfy MLRP do not exist, it is straightforward to show that for binary signal structures, the impact of social learning will be relatively small when the observing investor is sophisticated and relatively large when the observed investor is sophisticated. Finally, it is worth noting that, another investor's possession of the asset could still affect financially sophisticated investors' choices; similarly a financially unsophisticated investor's purchase decision - when accompanied by possession - could influence a peer's choice. Both of these effects would work through the social utility channel. Thus, we emphasize that these predictions of heterogeneous treatment effects apply to social learning effects alone, but not necessarily the overall peer effect.
} 


\section{Appendix B: Appendix Figures and Tables}

\section{Figure A.1: Investor 2's Alternative Outcomes}

Figure A.1.1: Amount invested

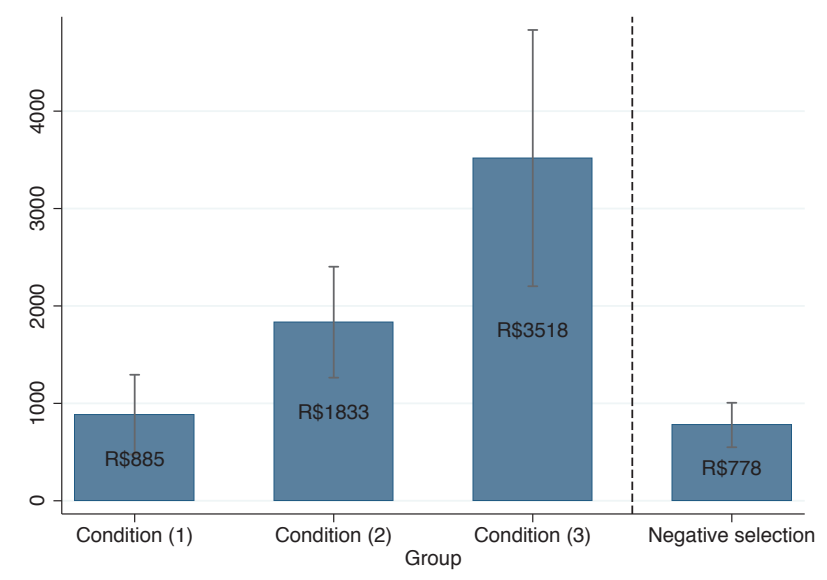

Figure A.1.2: Invested more than the minimum

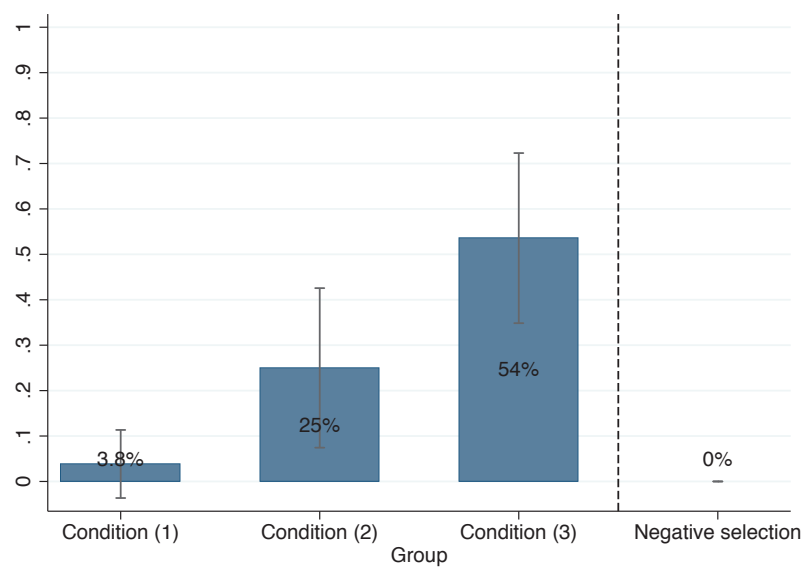

Note: Panel A.1.1 presents the mean (and 95\% confidence interval) of amount invested for each group of investor 2's. Panel A.1.2 presents the mean (and 95\% confidence interval) of a dummy variable equal to one if the investor invested more than the minimum amount for each group of investor 2's. Investors in conditions (1) to (3) have peers who wanted the asset. These investors were randomly allocated to one of these 3 groups. Those in condition (1) had no information about their peers. Those in condition (2) had information that their peers wanted to purchase the asset but had that choice rejected by the lottery. Those in condition (3) had information that their peers wanted and received the asset. Investors in the negative selection group have peers who did not want to purchase the asset (and received no information about their peer). 
Figure A.2: Heterogeneity of Social Learning Effects - Self-Assessed Measure of Financial Literacy

Figure A.2.1: Investor 2 is financially sophisticated

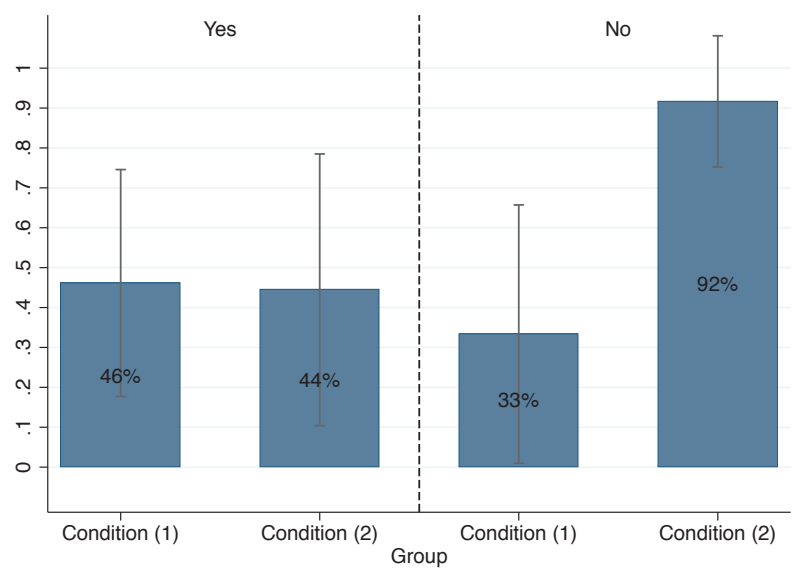

Figure A.2.2: Associated investor 1 is financially sophisticated

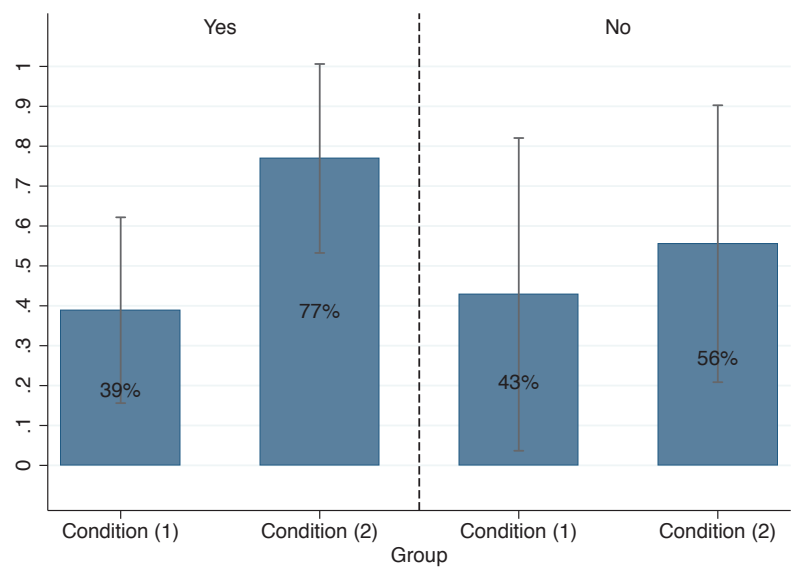

Note: Figure A.2.1 presents the mean (and 95\% confidence intervals) of take-up rates for investor 2's in conditions (1) and (2), separately for those who are and who are not financially sophisticated. Figure A.2.2 presents the take-up rates separately for those whose associated investor 1's are and who are not a financially sophisticated. Investors in conditions (1) and (2) have peers who wanted the asset. Those in condition (1) had no information about their peers. Those in condition (2) had information that their peers wanted to purchase the asset but had that choice rejected by the lottery. The financial sophistication variable is based on a self-assessment question conducted in a follow-up survey, where investors were asked to rank their level of financial sophistication from 1 (very low) to 7 (very high). Investors who reported 4 or higher were classified as financially sophisticated 
Table A.1: Covariates Balance - Other Randomizations

\begin{tabular}{|c|c|c|c|c|c|c|c|c|}
\hline & \multicolumn{4}{|c|}{ Assignment to investor 1 or investor 2} & \multicolumn{4}{|c|}{ Lottery for investor 1's who wanted the asset } \\
\hline & Investor 1 & Investor 2 & $\begin{array}{c}\text { p-value of } \\
\text { test } \\
(1)=(2)\end{array}$ & $\mathrm{N}$ & Won & Lost & $\begin{array}{c}\text { p-value of } \\
\text { test } \\
(5)=(6)\end{array}$ & $\mathrm{N}$ \\
\hline & $(1)$ & $(2)$ & $(3)$ & $(4)$ & $(5)$ & (6) & $(7)$ & $(8)$ \\
\hline Age & $\begin{array}{l}39.12 \\
(1.14)\end{array}$ & $\begin{array}{l}37.18 \\
(1.12)\end{array}$ & 0.22 & 300 & $\begin{array}{l}39.47 \\
(2.34)\end{array}$ & $\begin{array}{l}39.71 \\
(2.23)\end{array}$ & 0.94 & 78 \\
\hline Gender (=1 If male) & $\begin{array}{c}0.747 \\
(0.036)\end{array}$ & $\begin{array}{c}0.613 \\
(0.040)\end{array}$ & 0.01 & 300 & $\begin{array}{c}0.861 \\
(0.058)\end{array}$ & $\begin{array}{c}0.690 \\
(0.072)\end{array}$ & 0.07 & 78 \\
\hline Married & $\begin{array}{c}0.440 \\
(0.041)\end{array}$ & $\begin{array}{c}0.387 \\
(0.040)\end{array}$ & 0.35 & 300 & $\begin{array}{c}0.472 \\
(0.084)\end{array}$ & $\begin{array}{c}0.405 \\
(0.077)\end{array}$ & 0.56 & 78 \\
\hline Single & $\begin{array}{c}0.527 \\
(0.041)\end{array}$ & $\begin{array}{c}0.587 \\
(0.040)\end{array}$ & 0.30 & 300 & $\begin{array}{c}0.528 \\
(0.084)\end{array}$ & $\begin{array}{c}0.500 \\
(0.078)\end{array}$ & 0.81 & 78 \\
\hline Earnings & $\begin{array}{l}5,000 \\
(499)\end{array}$ & $\begin{array}{l}4,000 \\
(507)\end{array}$ & 0.22 & 270 & $\begin{array}{l}5,000 \\
(925)\end{array}$ & $\begin{array}{l}5,000 \\
(754)\end{array}$ & 0.59 & 74 \\
\hline $\begin{array}{l}\text { Relationship with } \\
\text { peer (=1 if family) }\end{array}$ & - & - & - & - & $\begin{array}{c}0.44 \\
(0.08)\end{array}$ & $\begin{array}{c}0.60 \\
(0.08)\end{array}$ & 0.19 & 78 \\
\hline
\end{tabular}

Notes: Columns 1 and 2 present the averages of the corresponding variable, respectively, for investors assigned to be in the role of investor 1 and for those assigned to be in the role of investor 2. Robust standard errors in parentheses. Relationship with peer is not considered in this comparison since this variable is equal for both groups by construction. Column 3 presents the p-value of an F-test that the mean of the corresponding variable is the same for these two groups. Column 5 presents the averages for investor 1's who wanted the asset and won the lottery, while column 6 presents the averages for investor 1's who wanted the asset but did not win the lottery. Column 7 presents the p-value of an F-test that the mean of the corresponding variable is the same for these two groups. For earnings, we present the median and the p-value of a test that the median of this variable is the same for the corresponding groups. The sample size for the earnings variable is smaller due to missing values. 
Table A.2: Follow-up Survey

\begin{tabular}{|c|c|c|c|}
\hline Question & Universe & Sample size & Results \\
\hline \multicolumn{4}{|c|}{ Panel A: Financial Literacy Survey } \\
\hline $\begin{array}{l}\text { 1. Self-assessed } \\
\text { financial literacy } \\
\text { (range: } 1-7)\end{array}$ & $\begin{array}{l}\text { Investor } 2 \text { 's in conditions (1) } \\
\text { and (2), and their associated } \\
\text { investor 1's }\end{array}$ & 90 (out of 100 ) & $\begin{array}{l}\text { Mean: } 3.8 \\
\text { Standard deviation: } 1.7 \\
\text { Proportion } \geq 4: 58.89 \%\end{array}$ \\
\hline $\begin{array}{l}\text { 2. Interest rate } \\
\text { compounding question }\end{array}$ & $\begin{array}{l}\text { Investor } 2 \text { 's in conditions (1) } \\
\text { and }(2) \text {, and their associated } \\
\text { investor } 1 \text { 's }\end{array}$ & 90 (out of 100 ) & Correct: $85.56 \%$ \\
\hline 3. Inflation question & $\begin{array}{l}\text { Investor } 2 \text { 's in conditions (1) } \\
\text { and (2), and their associated } \\
\text { investor } 1 \text { 's }\end{array}$ & 90 (out of 100$)$ & Correct: $85.56 \%$ \\
\hline 4. Diversification question & $\begin{array}{l}\text { Investor } 2 \text { 's in conditions (1) } \\
\text { and }(2), \text { and their associated } \\
\text { investor } 1 \text { 's }\end{array}$ & 90 (out of 100 ) & Correct: $67.78 \%$ \\
\hline 5. Bond prices question & $\begin{array}{l}\text { Investor } 2 \text { 's in conditions (1) } \\
\text { and (2), and their associated } \\
\text { investor 1's }\end{array}$ & 90 (out of 100$)$ & Correct: $14.44 \%$ \\
\hline Questions (2)-(5) & & & $\begin{array}{l}0 \text { correct answers: } 5.56 \% \\
1 \text { correct answer: } 5.56 \% \\
2 \text { correct answers: } 32.22 \% \\
3 \text { correct answers: } 43.33 \% \\
4 \text { correct answers: } 13.33 \%\end{array}$ \\
\hline
\end{tabular}

Panel B: Questions Regarding the Sales Call

\begin{tabular}{|c|c|c|c|}
\hline $\begin{array}{l}\text { 1. Effect of lottery } \\
\text { on purchase decision }\end{array}$ & $\begin{array}{l}\text { Investor } 2 \text { 's in conditions (1) } \\
(2) \text { and ( } 3)\end{array}$ & 69 (out of 78 ) & No: $95.65 \%$ \\
\hline $\begin{array}{l}\text { 2. Believed purchase decision } \\
\text { could have been changed } \\
\text { after lottery }\end{array}$ & $\begin{array}{l}\text { Investor } 2 \text { 's in conditions (1) } \\
(2) \text { and (3) }\end{array}$ & 69 (out of 78 ) & No: $94.20 \%$ \\
\hline $\begin{array}{l}\text { 3. Peer's lottery result } \\
\text { affected beliefs about } \\
\text { own lottery }\end{array}$ & $\begin{array}{l}\text { Investor } 2 \text { 's in conditions } \\
(2) \text { and }(3)\end{array}$ & 47 (out of 52 ) & No: $100 \%$ \\
\hline $\begin{array}{l}\text { 4. Peer's lottery result } \\
\text { affected beliefs about } \\
\text { quality of the asset }\end{array}$ & $\begin{array}{l}\text { Investor } 2 \text { 's in conditions } \\
(2) \text { and }(3)\end{array}$ & 47 (out of 52 ) & No: $97.87 \%$ \\
\hline $\begin{array}{l}\text { 5. Was (not) wanting something } \\
\text { your peer could not have } \\
\text { a significant factor in decision? }\end{array}$ & Investor 2's in condition (2) & 20 (out of 24 ) & No: $100 \%$ \\
\hline $\begin{array}{l}\text { 6. Effect of peer decision on } \\
\text { beliefs about quality } \\
\text { of the asset }\end{array}$ & $\begin{array}{l}\text { Investor 2's in conditions } \\
(2) \text { and }(3)\end{array}$ & 48 (out of 52 ) & $\begin{array}{l}\text { Positive update: } 66.67 \% \\
\text { Negative update: } 2.08 \% \\
\text { No update: } 31.24 \%\end{array}$ \\
\hline $\begin{array}{l}\text { 7. Was wanting to have the } \\
\text { same financial return as your } \\
\text { peer a significant factor in decision? }\end{array}$ & $\begin{array}{l}\text { Investor } 2 \text { 's in condition ( } 3 \text { ) } \\
\text { who wanted the asset }\end{array}$ & 25 (out of 26 ) & Yes: $60 \%$ \\
\hline $\begin{array}{l}\text { 8. Was wanting to have the same } \\
\text { asset as your peer to talk about } \\
\text { the asset a significant factor in decision? }\end{array}$ & $\begin{array}{l}\text { Investor } 2 \text { 's in condition ( } 3 \text { ) } \\
\text { who wanted the asset }\end{array}$ & 25 (out of 26 ) & Yes: $44 \%$ \\
\hline $\begin{array}{l}\text { 9. Did you think about } \\
\text { what your peer could do } \\
\text { with the return? }\end{array}$ & $\begin{array}{l}\text { Investor } 2 \text { 's in condition ( } 3 \text { ) } \\
\text { who wanted the asset }\end{array}$ & 25 (out of 26 ) & Yes: $80 \%$ \\
\hline $\begin{array}{l}\text { 10. Was the fear of not having } \\
\text { a return your peer could } \\
\text { have a significant factor in decision? }\end{array}$ & $\begin{array}{l}\text { Investor } 2 \text { 's in condition ( } 3 \text { ) } \\
\text { who wanted the asset }\end{array}$ & 25 (out of 26 ) & Yes: $32 \%$ \\
\hline $\begin{array}{l}\text { 11. Did you believe the } \\
\text { information provided } \\
\text { by the broker? }\end{array}$ & $\begin{array}{l}\text { Investor 2's in conditions } \\
(2) \text { and (3) }\end{array}$ & 47 (out of 52 ) & Yes: $97.87 \%$ \\
\hline $\begin{array}{l}\text { 12. Were you concerned about } \\
\text { your decision being revealed } \\
\text { to other clients? }\end{array}$ & $\begin{array}{l}\text { Investor 2's in conditions } \\
(2) \text { and }(3)\end{array}$ & 47 (out of 52 ) & Yes: $89.36 \%$ \\
\hline
\end{tabular}

Notes: the follow-up survey was conducted between November 26, and December 7, 2012. From the universe of investor 2's in conditions (1)-(3) and investor 1's associated with investor 2's in conditions (1) or (2) (128 investors in total), we collected information on 117 investors. Not all of those investors were asked all of the questions. This table reports, for each question, which investors answered it, the number of responses, and the results. 
Table A.3: Permutation Tests (p-values)

\begin{tabular}{cccc}
\hline Dependent variable & Take-up rates & Amount invested & $\begin{array}{c}\text { Invested more } \\
\text { than minimum }\end{array}$ \\
& $(1)$ & $(2)$ & $(3)$ \\
\hline
\end{tabular}

Panel A: Main results

Learning alone

(Condition (2) - Condition (1))
$[0.052]^{*}$
$[0.012]^{* *}$
$[0.047]^{* *}$

Learning and possession

$[0.000]^{* * *}$

$[0.000]^{* * *}$

$[0.000]^{* * *}$

(Condition (3) - Condition (1))

Possession alone

(Condition (3) - Condition (2))

$[0.063]^{*} \quad[0.011]^{* *} \quad[0.047]^{* *}$

Negative selection

(Negative selection - Condition (1))

$[0.812] \quad[0.646]$

$[0.270]$

Panel B: Heterogeneity

Learning by

Sophisticated

$[0.675]$

Non-sophisticated

$[0.008]^{* * *}$

$[0.004]^{* * *}$

$[0.083]^{*}$

Difference

$[0.053]^{*}$

$[0.071]^{*}$

$[0.428]$

$\frac{\text { Learning from }}{\text { Sophisticated }}$

$[0.038]^{* *}$

$[0.009]^{* * *}$

$[0.028]^{* *}$

Non-sophisticated

[0.801]

[0.816]

[1.000]

Difference

[0.434]

[0.155]

$[0.028]^{* *}$

Notes: This table presents the results of two-sided permutation tests with 10,000 replications for the main results of the paper. Panel A reports p-values from permutation tests for pairwise comparisons of the conditions of interest using three different outcome variables: take-up rates, amount invested, and a dummy variable indicating whether the investor invested more than the minimum amount. Panel B reports p-values from permutation tests for the heterogeneity results using the self-assessed measure of financial literacy. ${ }^{*}$ significant at $10 \%$; $*$ significant at $5 \% ; * * *$ significant at $1 \%$. 
Table A.4: Probit Average Marginal Effects - Peer Effects, Social Learning, Social Utility, and Selection: Take-up Rates

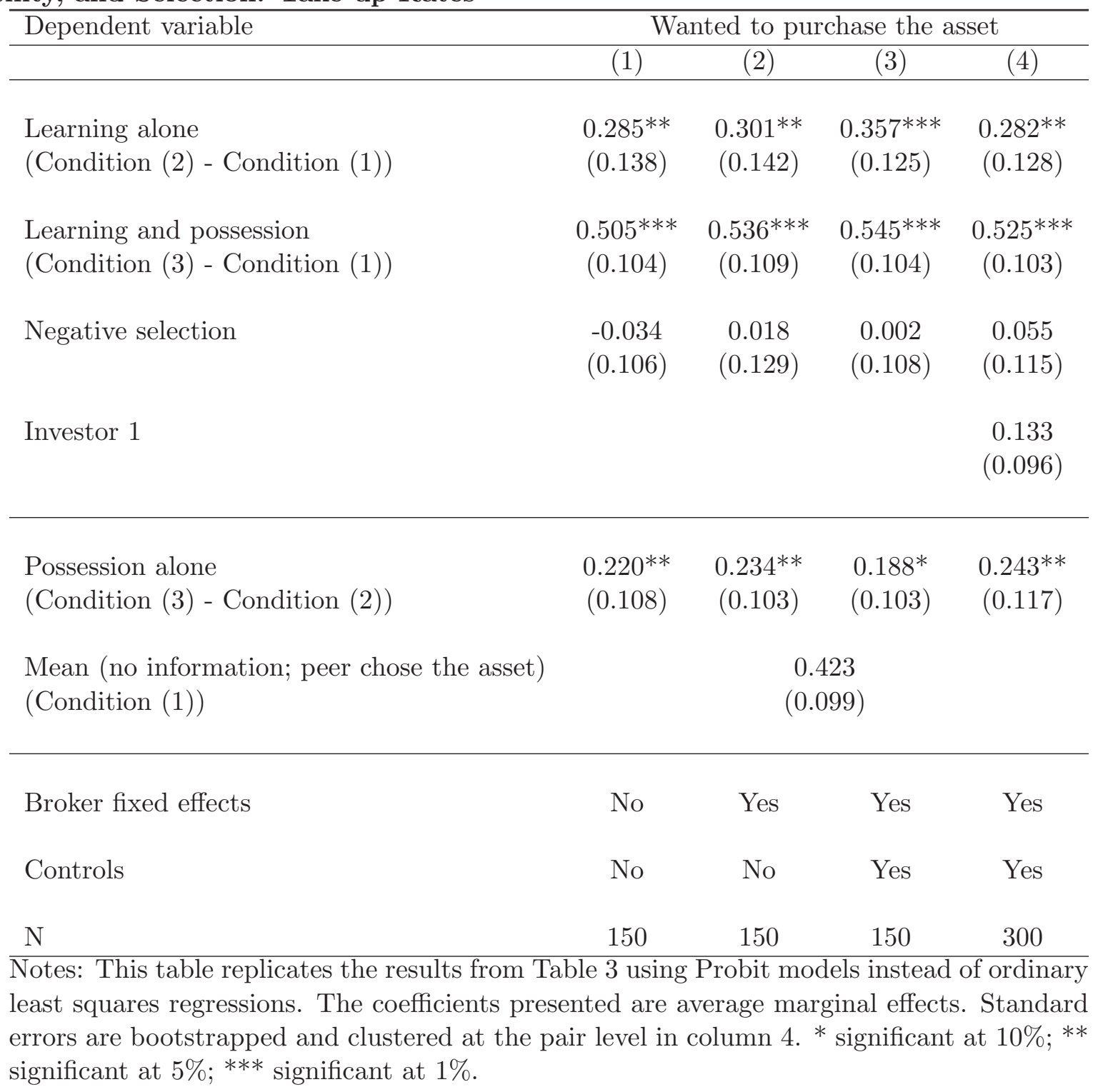


Table A.5: Logit Average Marginal Effects - Peer Effects, Social Learning, Social Utility, and Selection: Take-up Rates

\begin{tabular}{|c|c|c|c|c|}
\hline \multirow[t]{2}{*}{ Dependent variable } & \multicolumn{4}{|c|}{ Wanted to purchase the asset } \\
\hline & $(1)$ & $(2)$ & $(3)$ & $(4)$ \\
\hline $\begin{array}{l}\text { Learning alone } \\
\text { (Condition (2) - Condition (1)) }\end{array}$ & $\begin{array}{c}0.285^{* *} \\
(0.138)\end{array}$ & $\begin{array}{c}0.295^{* *} \\
(0.143)\end{array}$ & $\begin{array}{c}0.355^{* * *} \\
(0.124)\end{array}$ & $\begin{array}{c}0.275^{* *} \\
(0.127)\end{array}$ \\
\hline $\begin{array}{l}\text { Learning and possession } \\
\text { (Condition (3) - Condition (1)) }\end{array}$ & $\begin{array}{c}0.505^{* * *} \\
(0.104)\end{array}$ & $\begin{array}{c}0.542^{* * *} \\
(0.112)\end{array}$ & $\begin{array}{c}0.556^{* * *} \\
(0.103)\end{array}$ & $\begin{array}{c}0.527 * * * \\
(0.106)\end{array}$ \\
\hline Negative selection & $\begin{array}{l}-0.034 \\
(0.106)\end{array}$ & $\begin{array}{c}0.018 \\
(0.131)\end{array}$ & $\begin{array}{l}-0.006 \\
(0.107)\end{array}$ & $\begin{array}{c}0.052 \\
(0.116)\end{array}$ \\
\hline Investor 1 & & & & $\begin{array}{c}0.132 \\
(0.096)\end{array}$ \\
\hline $\begin{array}{l}\text { Possession alone } \\
\text { (Condition (3) - Condition (2)) }\end{array}$ & $\begin{array}{l}0.220^{* *} \\
(0.108)\end{array}$ & $\begin{array}{c}0.247^{* *} \\
(0.105)\end{array}$ & $\begin{array}{l}0.202^{*} \\
(0.104)\end{array}$ & $\begin{array}{c}0.252^{* *} \\
(0.120)\end{array}$ \\
\hline $\begin{array}{l}\text { Mean (no information; peer chose the asset) } \\
\text { (Condition (1)) }\end{array}$ & & & & \\
\hline Broker fixed effects & No & Yes & Yes & Yes \\
\hline Controls & No & No & Yes & Yes \\
\hline $\mathrm{N}$ & 150 & 150 & 150 & 300 \\
\hline Broker fixed effects & No & Yes & Yes & Yes \\
\hline Controls & No & No & Yes & Yes \\
\hline $\mathrm{N}$ & 150 & 150 & 150 & 300 \\
\hline
\end{tabular}

Notes: This table replicates the results from Table 3 using Logit models instead of ordinary least squares regressions. The coefficients presented are average marginal effects. Standard errors are bootstrapped and clustered at the pair level in column $4 .{ }^{*}$ significant at $10 \%$; ** significant at $5 \%$; *** significant at $1 \%$. 


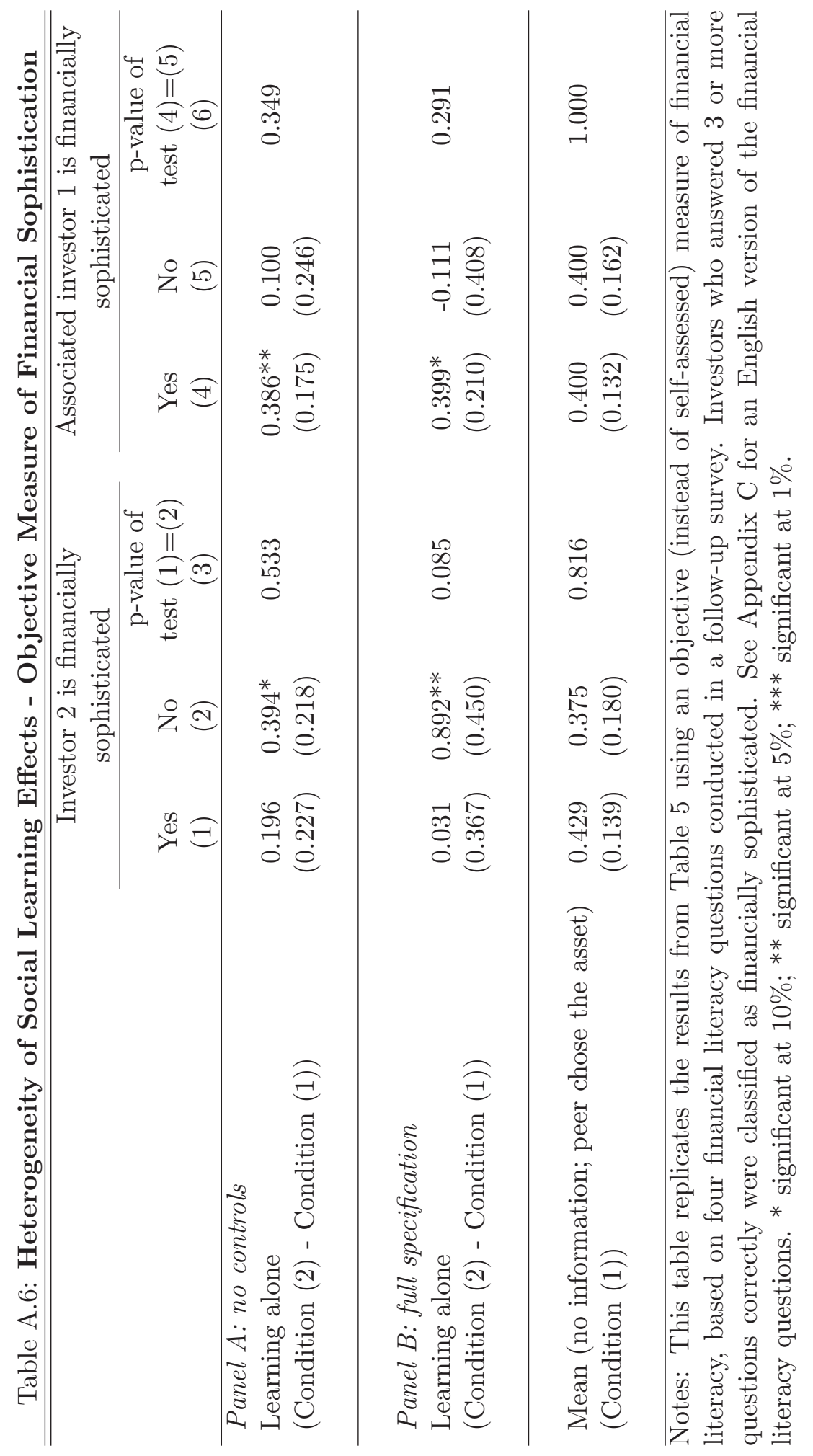




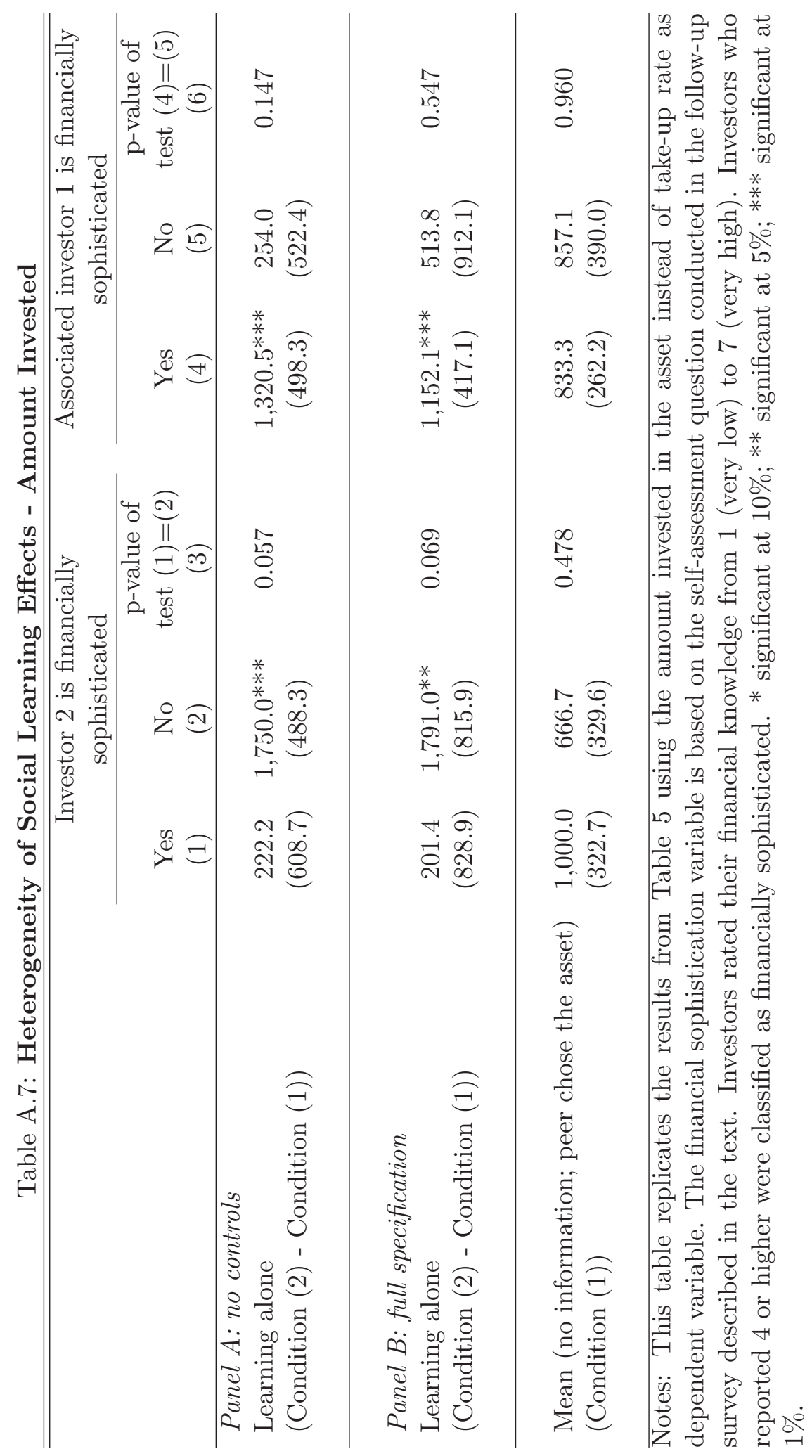




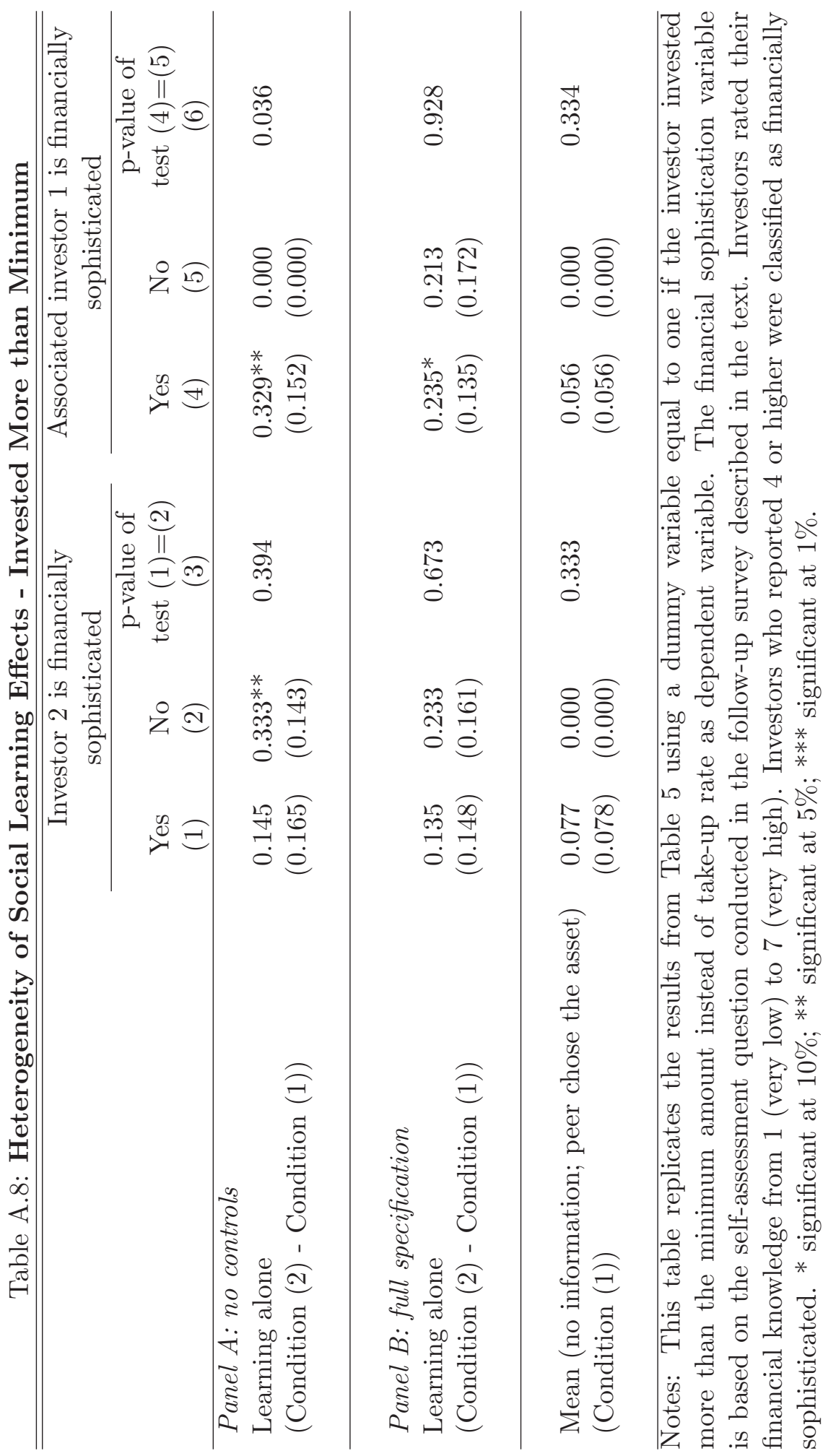




\section{Appendix C: Experimental Documentation}

We enclose here English versions of the Qualtrics scripts used by the brokers in the sales phone calls, first to investor 1's and then to investor 2's. Then we enclose English versions of the follow-up survey questionnaires. After these documents, we enclose a picture of the implementation of the experiment, displaying the brokers and the RA. 


\section{Client number}

Name of broker making phone call

Client number

\section{Introduction}

\section{Description of asset}

Combination of two investments:

- Fundo Long-Short multi-mercado (read brochure)

- LCl de 98\% do CDI (read brochure)

Minimum investment:

- $R \$ 1,000$ in $\mathrm{LCl}$ and $\mathrm{R} \$ 1,000$ in Fundo Long-Short

Maximum investment:

$-\mathrm{R} \$ 10,000$ in $\mathrm{LCl}$ and no limits in Fundo Long-Short

\section{Observations to be told to client:}

1) Special LCI usually not avaliable to clients. LCI typically available to clients has return of $97 \%$ of CDI and minimum investment of $R \$ 10,000$

2) Emphasize that product can only be purchased during this call (take it or leave it): will not be sold on other occasions

3) Remind that $\mathrm{LCl}$ is exempt from income tax

4) Explain that only new resources will be accepted (and not resources already invested with the brokerage)

\section{Limited supply}

This is a special asset, only available in limited supply, and only to special clients I ke you.

As so, unfortunately, some of the clients that want the asset will not be able to actually purchase it.

Since we are a company that always wants to be as fair as possible, we want to give a chance to all the special clients we are calling and who are interested in the product. In addition to that, we would like to give the same chance to everyone.

Because of that, we will use a lottery to determine which clients will actually be able to implement the purchase, among those that chose to purchase the asset.

In this lottery half (50\%) of the clients that choose to purchase the asset will have their choices authorized and implemented.

The lottery consists in drawing a random integer number between 1 and 100 . If the number is 50 or less, the lottery will not authorize the investment. If the number is greater than 50 , the lottery will authorize and make the investment.

It is important that you know that the decision you will make now if final. If you decide to purchase the asset, you will be authorizing the purchase. Therefore, if the lottery authorizes the purchase, the investment will be made.

Take advantage of this great opportunity to buy this exclusive product!

\section{Investment decision}


Ask the client what their decision is
Wants to invest
Does not want to invest

How much does he want to invest in the Fundo Long-Short multi-mercado?

\section{Investment authorization}

A random number will now be drawn to determine whether or not you will be able to actually make the investment. The random number is $\$\{\mathrm{e}: / /$ Field/random $\}$

Due to the outcome of the lottery, your investment was not authorized.

Due to the outcome of the lottery, your investment was authorized.

Was the investment authorized?

$\mathrm{O}$ Yes

\section{End of Call and Summary}

Finish the call

This is the summary of the call. Please put the following information in your Excel spreadsheet of communication with the clients:

Client number: \$\{q://QID20/ChoiceTextEntryValue\}

Did this client want to invest in the product? Yes

Amount invested in the Fundo Long-Short: \$\{q://QID18/ChoiceTextEntryValue

Amount invested in the LCI: \$\{q://QID26/ChoiceTextEntryValue\}

Was this client authorized to make the investment? Yes

This is the summary of the call. Please put the following information in your Excel spreadsheet of communication with the clients:

Client number: \$\{q://QID20/ChoiceTextEntryValue\}

Did this client want to invest in the product? Yes

Amount invested in the Fundo Long-Short: \$\{q://QID18/ChoiceTextEntryValue

Amount invested in the LCI: \$\{q://QID26/ChoiceTextEntryValue\} 
Was this client authorized to make the investment? No

This is the summary of the call. Please put the following information in your Excel spreadsheet of communication with the clients:

Client number: \$\{q://QID20/ChoiceTextEntryValue\}

Did this client want to invest in the product? No

Amount invested in the Fundo Long-Short: 0

Amount invested in the LCl: 0

Was this client authorized to make the investment? N/A 


\section{Client number}

Name of broker making phone call

Client number

Number of client of the (first) friend of this investor

\section{Previous Choice by FRIEND 1}

Did the first friend of this investor want to invest in this asset?
$\mathrm{Y}$ Yes
No

Was the first friend of this investor authorized to make the investment?

$\mathrm{Y}$ Yes

No

\section{Introduction}

\section{Description of Asset}

Combination of two investments:

- Fundo Long-Short multi-mercado (read brochure)

- $\mathrm{LCl}$ de $98 \%$ do CDI (read brochure)

Minimum investment:

- $\mathrm{R} \$ 1,000$ in $\mathrm{LCl}$ and $\mathrm{R} \$ 1,000$ in Fundo Long-Short

Maximum investment:

$-\mathrm{R} \$ 10,000$ in $\mathrm{LCl}$ and no limits in Fundo Long-Short

Observations to be told to client:

1) Special LCI usually not avaliable to clients. LCI typically available to clients has return of $97 \%$ of CDI and minimum

investment of $\mathrm{R} \$ 10,000$

2) Emphasize that product can only be purchased during this call (take it or leave it): will not be sold on other occasions

3) Remind that $\mathrm{LCl}$ is exempt from income tax

4) Explain that only new resources will be accepted (and not resources already invested with the brokerage)

\section{Limited Supply}

This is a special asset, only available in limited supply, and only to special clients I ke you. 
As so, unfortunately, some of the clients that want the asset will not be able to actually purchase it.

Since we are a company that always wants to be as fair as possible, we want to give a chance to all the special clients we are calling and who are interested in the product. In addition to that, we would like to give the same chance to everyone.

Because of that, we will use a lottery to determine which clients will actually be able to implement the purchase, among those that chose to purchase the asset.

In this lottery half $(50 \%)$ of the clients that choose to purchase the asset will have their choices authorized and implemented.

The lottery consists in drawing a random integer number between 1 and 100 . If the number is 50 or less, the lottery will

not authorize the investment. If the number is greater than 50 , the lottery will authorize and make the investment.

It is important that you know that the decision you will make now if final. If you decide to purchase the asset, you will be authorizing the purchase. Therefore, if the lottery authorizes the purchase, the investment will be made.

Take advantage of this great opportunity to buy this exclusive product!

\section{Only Learning Treatment}

Before asking whether or not the client wants to purchase the asset, tell him the information associated with the choice of the first friend and the outcome of the lottery for the first friend:

"We would like to inform you, before you make your decision, that [FIRST FRIEND'S NAME], your [RELATIONSHIP TO THIS CLIENT], received the same offer today. He/she chose to purchase the product. However, the lottery did not authorize him/her to make the purchase, so he/she will not make the investment."

SUMMARIZING: He/she wanted to make the investment but was not able to invest.

\section{Possession and Learning Treatment}

Before asking whether or not the client wants to purchase the asset, tell him the information associated with the choice of the first friend and the outcome of the lottery for the first friend:

"We would like to inform you, before you make your decision, that [FIRST FRIEND'S NAME], your [RELATIONSHIP TO THIS CLIENT], received the same offer today. He/she chose to purchase the product. The lottery authorized him/her to make the purchase, so he/she will make the investment."

SUMMARIZING: He/she wanted to make the investment and was able to invest.

\section{Investment Decision}

Ask the client what their decision is

Wants to invest

Does not want to invest

How much does he want to invest in the Fundo Long-Short multi-mercado?

How much does he want to invest in the LCl? 
Investment Authorization

A random number will now be drawn to determine whether or not you will be able to actually make the investment. The random number is $\$\{\mathrm{e}: / /$ Field/random\}

Due to the outcome of the lottery, your investment was not authorized.

Due to the outcome of the lottery, your investment was authorized.

Was the investment authorized?

Yes

No

\section{Relationship with First Investor, End of Call, and Summary}

Had you previously heard about this offer/this product from [FIRST FRIEND'S NAME]?

$\mathrm{Y}$ Yes

No

What is your degree of relationship with [FIRST FRIEND'S NAME]? Examples: sibling, parent, friend, co-worker, etc.

(

Finish the phone call

This is the summary of the call. Please put the following information in your Excel spreadsheet of communication with the clients:

Client number: \$\{q://QID27/ChoiceTextEntryValue\}

First friend's client number: \$\{q://QID30/ChoiceTextEntryValue\}

Did the first friend want to invest in the product? \$\{q://QID21/ChoiceGroup/SelectedChoices\}

Was the first friend authorized to make the investment? \$\{q:/QID25/ChoiceGroup/SelectedChoices $\}$

Did this client (second friend) want to invest in the product? Yes

Amount invested in the Fundo Long-Short: \$\{q://QID28/ChoiceTextEntryValue

Amount invested in the LCI: \$\{q://QID38/ChoiceTextEntryValue $\}$

Was this client authorized to make the investment? Yes

This is the summary of the call. Please put the following information in your Excel spreadsheet of communication with the clients:

Client number: \$\{q://QID27/ChoiceTextEntryValue\}

First friend's client number: \$\{q://QID30/ChoiceTextEntryValue\}

Did the first friend want to invest in the product? \$\{q://QID21/ChoiceGroup/SelectedChoices $\}$ 
Was the first friend authorized to make the investment? \$\{q://DID/ChoiceGroup/SelectedChoices $\}$

Did this client (second friend) want to invest in the product? Yes

Amount invested in the Fundo Long-Short: \$\{q://QID28/ChoiceTextEntryValue

Amount invested in the LCI: \$\{q://QID38/ChoiceTextEntryValue\}

Was this client authorized to make the investment?: No

This is the summary of the call. Please put the following information in your Excel spreadsheet of communication with the clients:

Client number: \$\{q://QID27/ChoiceTextEntryValue\}

First friend's client number: \$\{q://QID30/ChoiceTextEntryValue\}

Did the first friend want to invest in the product? \$\{q://QID21/ChoiceGroup/SelectedChoices $\}$

Was the first friend authorized to make the investment? \$\{q://QID25/ChoiceGroup/SelectedChoices $\}$

Did this client (second friend) want to invest in the product? No

Amount invested in the Fundo Long-Short: 0

Amount invested in the LCI: 0

Was this client authorized to make the investment?: N/A 


\section{Follow-up Survey}

\section{Financial Literacy Survey}

This survey was administered to investor 2's in conditions 1 and 2, and to their associated investor 1 's.

(1) On a scale from 1 to 7 , where 1 means very low and 7 means very high, how would you assess your overall financial knowledge?

1. Very low

2 .

3 .

4 .

5 .

6.

7. Very high

(2) Suppose you had $\$ 100$ in a savings account and the interest rate was $8 \%$ per year. After 5 years, how much do you think you would have in the account if you left the money in the account to grow:
a. More than $\$ 108$
b. Exactly $\$ 108$
c. Less than $\$ 108$
d. Do not know
e. Refuse to answer

(3) Imagine that the interest rate on your savings account was 5\% per year and inflation was $7 \%$ per year. After 1 year, using the money that will be in the account, would you be able to buy:
a. More than what you can buy today
b. Exactly the same as what you can buy today
c. Less than what you can buy today
d. Do not know
e. Refuse to answer

(4) Do you think that the following statement is true or false? "Buying a single company stock usually provides a safer return than a stock mutual fund."
a. True
b. False 
c. Do not know

d. Refuse to answer

(5) If interest rates rise, what will typically happen to bond prices?
a. They will rise
b. They will fall
c. They will stay the same
d. There is no relationship between bond prices and the interest rates
e. Do not know
f. Refuse to answer

\section{Questions Regarding the Sales Call}

(1) For investor 2's in conditions 1, 2, and 3

When the asset was offered to you in the beginning of the year, we had to use a lottery given that the asset was in limited supply. At that moment, you decided to purchase (not purchase) the asset. Was the presence of the lottery a significant factor in your decision?
a. Yes
b. No

(2) For investor 2's in conditions 1, 2, and 3

Before the result of the lottery, you made a purchase decision. Did you believe you could have changed your decision after the lottery?
a. Yes
b. No

(3) For investor 2's in conditions 2 and 3

When the asset was offered to you, you were informed that [NAME OF THE ASSOCIATED INVESTOR 1] wanted the asset, but that he/she lost the lottery (and he/she won the lottery).

In the lottery, you had 50\% chance of winning and 50\% chance of losing, independently of the result for [NAME OF THE ASSOCIATED INVESTOR 1]. When you were informed that [NAME OF THE ASSOCIATED INVESTOR 1] lost (won) the lottery, how did this affect your beliefs about the likelihood of winning the lottery?

a. It would be more likely to win the lottery

b. It would be less likely to win the lottery

c. The likelihood of winning the lottery would remain unchanged. 
(4) For investor 2 's in conditions 2 and 3

You were informed that [NAME OF THE ASSOCIATED INVESTOR 1] lost (won) the lottery. How did this affect your beliefs about the quality of the asset?

a. This should be a better investment.

b. This should be a worse investment.

c. No effect.

(5) For investor 2's in condition 2

Was wanting (not wanting) an asset that [NAME OF THE ASSOCIATED INVESTOR 1] could not have because he/she lost the lottery a significant factor in your decision?

a. Yes.

b. No.

(6) For investor 2's in conditions 2 and 3

You were informed that [NAME OF THE ASSOCIATED INVESTOR 1] wanted to purchase the asset. How did this affect your beliefs about the quality of the asset?

a. This should be a better investment.

b. This should be a worse investment.

c. No effect.

(7) For investor 2's in condition 3 who decided to purchase the asset

Was wanting to earn the same financial returns that [NAME OF THE ASSOCIATED INVESTOR 1] would earn a significant factor in your decision?

a. Yes.

b. No.

(8) For investor 2's in condition 3 who decided to purchase the asset

Was wanting the same asset that [NAME OF THE ASSOCIATED INVESTOR 1] had so that you could discuss the asset with him/her a significant factor in your decision?

a. Yes.

b. No.

(9) For investor 2's in condition 3 who decided to purchase the asset

Did you think about what [NAME OF THE ASSOCIATED INVESTOR 1] could do with the return from the asset when you made your decision?

a. Yes.

b. No. 
(10) For investor 2's in condition 3 who decided to purchase the asset

You were informed that [NAME OF THE ASSOCIATED INVESTOR 1] had the asset. Was the fear of not having a return he/she could have a significant factor in your decision?
a. Yes.
b. No.

(11) For investor 2's in conditions 2 and 3

The broker informed you that [NAME OF THE ASSOCIATED INVESTOR 1] wanted to purchase the asset. Did you believe in this information?
a. Yes.
b. No.

(12) For investor 2's in conditions 2 and 3

Your choices were never revealed to other clients. Still, were you concerned about this possibility when you decided to purchase (not to purchase) the asset?
a. Yes.
b. No. 
Figure A.3: Picture from the implementation

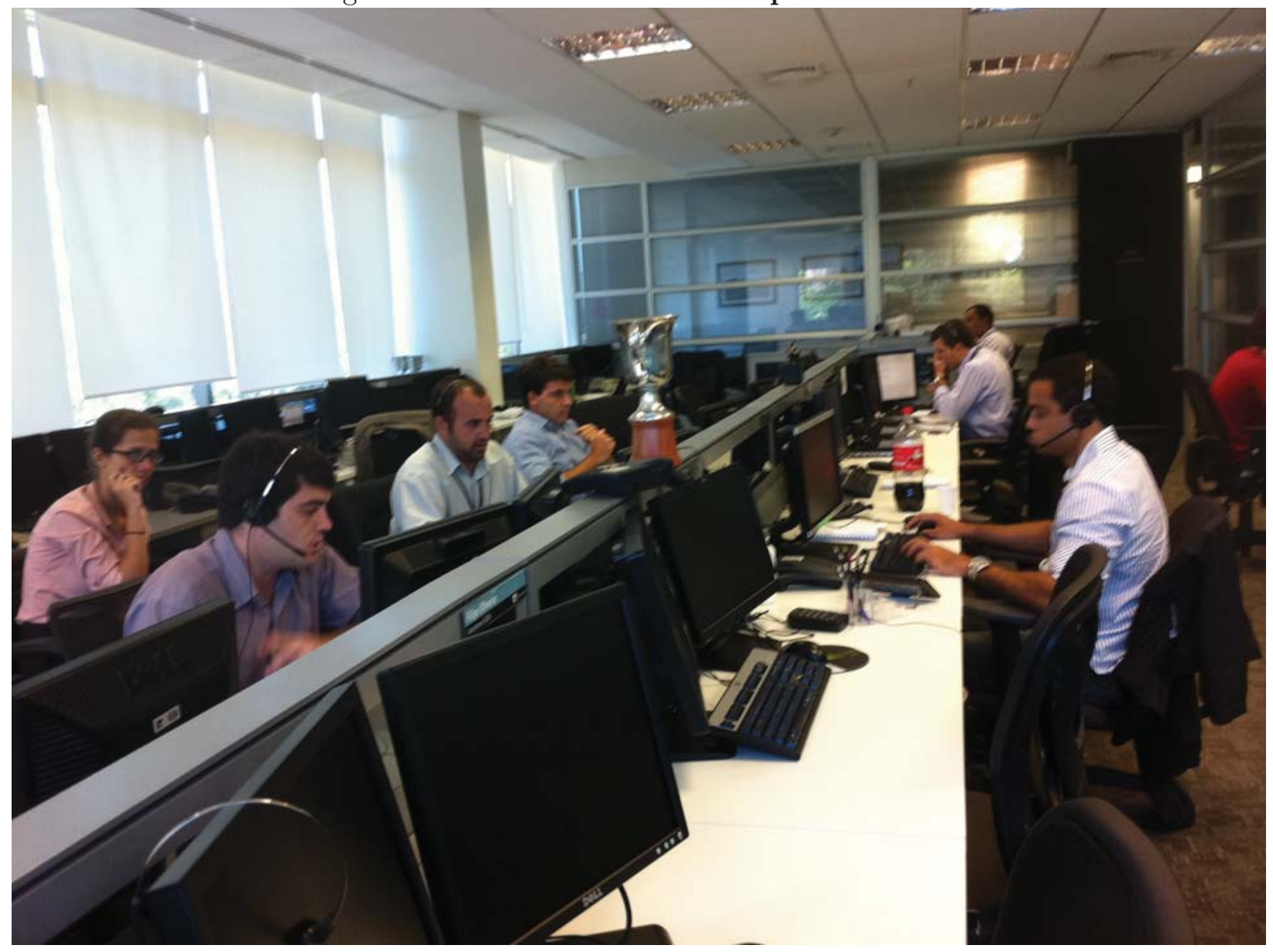

